Article

\title{
New Life for Disused Religious Heritage: A Sustainable Approach
}

\author{
Alessandro Lo Faro ${ }^{1, *(D)}$ and Alessia Miceli ${ }^{2}$ \\ 1 DICAr, Department of Civil Engineering and Architecture, University of Catania, 95125 Catania, Italy \\ 2 DICAr, Department of Civil Engineering and Architecture, University of Pavia, 27100 Pavia, Italy; \\ alessia.miceli@unipv.it \\ * Correspondence: alessandro.lofaro@unict.it; Tel.: +39-095-738-2527
}

check for

updates

Citation: Lo Faro, A.; Miceli, A. New Life for Disused Religious Heritage: A Sustainable Approach. Sustainability 2021, 13, 8187. https:// doi.org/10.3390/su13158187

Academic Editor: Asterios Bakolas

Received: 16 June 2021

Accepted: 18 July 2021

Published: 22 July 2021

Publisher's Note: MDPI stays neutral with regard to jurisdictional claims in published maps and institutional affiliations.

Copyright: (c) 2021 by the authors. Licensee MDPI, Basel, Switzerland. This article is an open access article distributed under the terms and conditions of the Creative Commons Attribution (CC BY) license (https:// creativecommons.org/licenses/by/ $4.0 /)$.

\begin{abstract}
The sustainable reuse of the built heritage is one of the main challenges of our time. Religious heritage, in particular, requires strong survey strategies and analyses in order to achieve consistent approaches for the conservation and transmission of its value, both material and immaterial. The exploitation of the latter is underpinned by knowledge analyses, prior to the conservation actions, with a focus not only on the techniques of material restoration but also on the values that it represents for the territory and local communities. With this aim, three case studies in Southern Italy are here presented, that offer a good example of how ecclesiastical heritage, although vast and diffuse, is still an undervalued asset. By combining accurate knowledge and historical research in comparison with the residual performance of the buildings, the results aim to demonstrate how integrated knowledge strategies can pursue more conscious choices of new possible uses for abandoned religious heritage, resulting in preserve their memory and add value in terms of social sustainability.
\end{abstract}

Keywords: religious heritage; sustainable reuse; social sustainability; hospitality; Sicily

\section{Introduction}

The historic built heritage represents an asset of unequalled relevance. It is important as it is the expression of art and culture of a period, embodies shared values and source of identity for the territories and their living communities [1] but it also has an unexpressed economic value [2]. The difficulties in the management and valorisation of such heritage are tangible. The European Commission defines it as "a common good and, like other such goods, it can be vulnerable to over-exploitation and under-funding, which can result in neglect, decay and, in some cases, oblivion" [3].

This is especially true for religious heritage since it represents a special kind of heritage that, for its immaterial and spiritual importance, distinguishes itself from the others.

In fact, religious sites and places "have a vital importance for safeguarding cultural and biological diversity for present and future generations"; collectively, the religious and sacred properties capture a range of cultural and natural diversity, and each can singularly demonstrate the spirit of a particular place [4,5].

Religious heritage is Europe's biggest living heritage [6], comprising more than 500,000 places of worship including churches, synagogues and mosques [7]. About $20 \%$ of the World Heritage List sites have a religious or spiritual nature, which justifies their outstanding universal value [5].

It is naturally recognized that these sites have always been strongly connected to the life of their community and arguably play, therefore, a pivotal role in the definition of the collective memory and identity of a place.

Their conservation also has a strong impact on the economy. According to the European Construction Industry Federation, in 2019, renovation and maintenance represented $28 \%$ of the value of Europe's construction industry [8]. This figure drastically increases if we 
consider the beneficial effects that the conservation of religious heritage has on tourism, creation of locally-rooted jobs, educational and volunteering opportunities, and regeneration of neglected areas [3].

The peculiar nature of these goods, alone, motivates their preservation, although this scope arguably faces many difficulties. On one side, in fact, the number of worshippers and ecclesiastics dramatically dwindled during the last decades [9], and this led to secularization, namely the decrease of the role of religious heritage in the community [10]. On the other side, a big part of ecclesiastical heritage is not profitable and counts on public or private funding for its sustenance [10]. In this scenario of prolonged economic difficulties and shortage of funding, the economic reason could prevail over the conservation need, as it is, in itself, not always economically sustainable.

Therefore, despite the increasing interest in its preservation, as proven, for example, by the birth of many non-governmental organizations-such as FRH (Belgium) and the Churches Conservation Trust (UK) among the most important-religious heritage is still perceived as vulnerable [11,12].

In order to support its exploitation and preservation, a key factor seems to be increasing understanding and raise awareness of the actual and potential role in the society.

According to these premises, our research wants to pay particular attention to the constraint enforced by the social factor: the perceptive-cultural constraint consists of the range of values contained in the considered heritage-aesthetic, historical, cultural, ethic. These values are impressed, sometimes even unconsciously, in the local community since its existence.

When we deal with the conservation of religious heritage, especially when it is put in place by means of new uses, we must keep in mind that we are dealing with extremely sensitive heritage, that not only often contains an outstanding cultural value, but also plays a significant role in defining the community's identity. This role is very sensitive and every action can damage this relationship. It is, therefore, important to calibrate the actions in order not to impair these qualities, but transmit them to the next generations.

At the same time, creating engagement with the heritage also depends on meeting the modern needs or resolve issues and creating opportunities that are perceived as relevant by the community.

Addressing these issues at the same time is a great challenge, requiring meaningful, but tailored and respectful actions. Hence, the methodology implemented focuses on accurate knowledge and comparing residual performances of the building with possible new uses.

In all the proposed new uses, developed according to the methodology below exposed, a strong potential in terms of social sustainability have been detected, because of their ability to increase the well-being of the local community, promote cohesion, stimulate social interactions and, ultimately, regenerate neglected areas.

The presented case studies demonstrate how religious heritage, even if dismissed and abandoned, still is an undervalued asset, and, through good reuse practices, they can simultaneously address two issues: preserving its memory and create added value.

\section{State of the Art}

In recent decades, the ever-increasing interest in the management and preservation of religious buildings has been tangible. To have an outline on this matter a review of reports, policies and academic production has been conducted.

In particular, the debate has been carried on by international heritage and policymaker agencies (such as UNESCO and ICCROM) as well as other non-governmental associations, both laic and religious, and scholars.

The recent focus is not only the conservation and preservation of religious heritage, but its potential and active participation in the generation of virtuous processes of enhancement of the life of the communities, that foster inclusion, participation, cohesion and social values. 
In November 2010 UNESCO recognized, in the Kyiv statement, the importance of religious heritage and the need for new ways for a dialogue between all the stakeholders, with particular focus on religious communities. A more inclusive participation is, therefore, encouraged in the implementation of practical actions, such as training programmes, for the management and conservation of the heritage, recognizing the role of religious communities in being custodians and continuous shapers of sacred places [13].

The European Commission, in a 2014 Communication, explores the challenges and opportunities for the heritage, particularly focusing on the ability to enhance the intrinsic social value, and highlighting the need for integrated approaches as the cultural heritage contribution to economic growth and social cohesion is still undervalued [3].

In June 2015, in another report, the European Parliament acknowledged religious heritage among the special categories of heritage called at becoming an opportunity and a challenge in "developing a true democratic and participative narrative for European heritage" [14].

One of the most recent international statements (2018) calls on the beneficial social effects of reusing the built heritage, particularly the one having strong immaterial values like religious buildings, stating that "by re-opening closed or disused spaces to the public, the adaptive re-use of our built heritage can generate new social dynamics in their surrounding areas and thereby contribute to urban regeneration. These projects offer the opportunity to involve citizens in the shaping of their living environment, resulting in greater sense of place and democracy" [15].

Dealing with religious heritage implies the responsibility to express these values while not undermining the original vocation of the building. The question of determining the appropriateness of new uses, different from the original ones, to be allocated in religious buildings have always been extremely debated.

Since the 1970s, the Conferenza Episcopale Italiana (Italian Catholic Bishop Authorities), exhorts to take into account different converging interests (devotional, cultural, touristic, technical) when reusing religious heritage. It also highlights the need for different levels of fruition, allowing new publics to its use and enhancing the role of the ecclesiastical heritage as not exclusively devotional but, on the contrary, strongly permeated with social and educational meanings [16].

In addition, a more recent communication from the same institution, states that the use of dismissed religious buildings for inconvenient use is strongly unrecommended, while uses related to pastoral and charitable activities are to be preferred, in virtue of their accordance with the values of the church, which does not pursue any economical profit [17].

At the same time, the Pontifical Council for Culture [18] have recognized that not pursuing economical profit does not mean leaving out the possibilities of a proper management, hence encouraging a renewal of the strategies regarding the church's asset, in order to valorise it and sustain its continuousness of use.

As noted by some authors $[9,19,20]$ this scope faces new emerging challenges. Firstly, religious places like convents, monasteries, abbeys and so on, have great significance to their community, and are often related — even physically - to sacred spaces still dedicated to religious practices. In the case of adaptively reusing the heritage, overlapping needs emerge, and new and different category of users are expected, increasing the level of complexity of the management [9].

Respecting the immaterial values of the building is a matter regarding the community as a whole, not just the faithful. While the worshippers find in sacred places their devotion, meaning, practices, that contribute to keeping alive the spirit of the place, in the same way cultural values are integral part of the sense of the place and foundations of the memory of the society. In fact, as portrayed by recent research, religious heritage is perceived important in the same way by both religious and non-religious people, and, consequently, the feeling of responsibility and belonging affect at least four different levels of entities: the active members of the congregation, the public Christian community, the local community 
and the national community [19]. This point explains the singular importance of heritage as a shared value of communities, despite of their religious belief.

The main implication of these assumption is that managers and practitioners of religious buildings deal with extremely sensitive heritage, unique and not renewable goods.

As the abovementioned policies pointed out, adaptive reuse of religious heritage is nowadays called at fostering multiple objectives, particularly those related to environmental concerns.

A widely used approach this matter acknowledges culture and social development as pillars of sustainability. The 2015 World Heritage Convention Policy, according to the UN's 2030 Agenda for Sustainable Development [21], strengthens the definition of sustainable development, recognizing three different levels of sustainability in addition to the environmental and economic ones: it is therefore introduced the level of inclusive social development which should "improve opportunities and reduce social or economic inequalities for local or other concerned communities, regardless of ethnicity, religion, economic, or any other status" [22]. The same agenda promulgates specific goals in regard to local development, sustainable tourism and enhancement, particularly addressed to the strengthening of small-scale economies, protection of local cultures and the environment (see, in particular, Goals 8.9; 11.4 and 12.b) [21].

These definitions give renewed light to the concept of social sustainability: as defined by WACOSS-Western Australian Council of Social Service- " social sustainability occurs when the formal and informal processes, systems, structures, and relationships actively support the capacity of current and future generations to create healthy and liveable communities. Socially sustainable communities are equitable, diverse, connected and democratic, and provide a good quality of life" [23].

On the other side, the concept of culture has been recently framed into discourses on sustainable development. The Burra Charter, for example, insists on the cultural significance of heritage, defined as "aesthetic, historic, scientific, social or spiritual value for past, present or future generations" that "may change over time and use" and underlines the interrelation with conservation, as the aim of the latter is to retain the cultural significance of a place [24].

It is worth noting that the concept of culture adds a considerable amount of complexity in defining the role and objectives of sustainable development. In fact, referring to Soini and Dessein, among the different levels of relation between culture and sustainability, some policies and theories move beyond the inclusion of culture as one of the pillars of sustainability, as is the case of environmental economic and social aspects, and elevate it as its foundation. According to this approach, culture becomes what enables sustainability, meaning that any kind of development is only possible in the light of a cultural process $[25,26]$.

According to these definitions, new strategies of heritage conservation can be defined, that particularly encompass the enhancement of the immaterial value of heritage.

New uses are fundamental to ensure the vitality of the built heritage, given that it is facing ever-increasing risks of oblivion, hence, allocating new functions that respond to socially relevant activities can be a way to achieve the sustainability of the action in a broader term.

By highlighting different interpretations of the sense of the place and extending the original themes of the building, it is possible to attract more users and create a new type of engagement and sense of belonging, improving the bond with the community without obliterating the original purpose of the building [27].

Attracting new users with different motivations, expectations and behavioural patterns, bring them to cohabit a shared space, enhancing socialization and cohesion [9].

Moreover, stakeholder engagement and inclusiveness are critical principles of sustainable development. In fact, encouraging the participation during the decision-making process of different stakeholders, being them economically involved or not, significantly improve the inclusiveness of the action [20], as proven by successful reuse practices across 
the world [28-30]. It is worth mentioning the virtuous case of Netherlands, that thanks to privatisation and encouraging laws, successfully reused religious heritage within a wide range of options, from community to private use, either residential or commercial [28]. Other successful case studies are the Cistercian monasteries in Portugal [29], reused for a variety of functions including education, exhibition and community spaces. All of these cases have a common base of a strong participation of the community and the original property owner in the decision-making process [28,30]

As fostered by the policies above mentioned and proved by research studies new approaches to reusing the religious heritage, high quality conservation projects preserve cultural heritage and community values at the same time [19] and enable an "uninterrupted connection between cultural heritage and modern needs while dialoguing with the original purpose" of the building [31-33].

The aim is to raise a renewed awareness and sensibility that supports public administrations, religious institutions and private investors in designing appropriate interventions with the purpose of exploiting the value of the asset, particularly according to the social dimension of sustainability, and supporting virtuous processes of circular economy [32,33].

It is also worth noting that the value expressed in terms of sustainability of a new use, not only derives from the results of the restoration/reuse process (attractiveness to new users, events and activities related to the renewed use of the heritage), but also generates since the process itself takes place. In fact, there is an additional value that derives from the effects that the activities strictly related to the conservation have on the local community, as local companies and workers are more likely to be involved in the process: their skill, knowledge and stricter relationships with the place and its stakeholders results in added value which is computable not only in economic terms but also as an intellectual capital. In this sense, the "focus shifts from heritage, as a given asset, to conservation processes as opportunities to increase intellectual capital" is an interesting factor in evaluating the added value that derives from reuse in terms of sustainability [34].

Provided that pursuing a sustainable approach adds value-but also complexityto the conservation action, it is necessary to use methods that allow the conservation practitioners to compare and evaluate proposals for reusing the built heritage. As emerged from several studies [35-40] the most broadly used methods are related to a multi-criteria evaluation, even if with peculiarities of specific cases.

These methods are based on four main steps:

- The determination of the objectives;

- The selection of the alternatives to be compared;

- The choice of the criteria;

- The application of the criteria to the selected alternatives;

- Finally, a sensitivity analysis to obtain meaningful results.

In all the reviewed cases, the choice of the criteria is arguably the most critical phase. Ferretti et al. [35] chose the criteria strictly on the basis of the objectives-such as quality of the context, presence of economic activities, flexibility, pedestrian accessibility, degree of conservation; Oppio et al. [36] defines the multi-dimensional impacts of the alternatives from a more spatial point of view-assessing the impacts of physical infrastructures, the environment, the social capital-and using a geographical information system to allow for visual and simultaneous analysis; Wang [37] focuses more on the evaluation of the interdependencies between the criteria and how to attribute different weights to each of them; others [38-40] combine different methods in order to use the most effective method according to the different phases, while achieving a consistent hierarchy of values.

In the case of religious heritage, most studies show how the criteria are usually chosen by research groups and experts of fields related to various fields, including entrepreneurship, tourism, but also and especially, architecture and cultural value.

It is worth noting that, without diverting the attention from the compatibility in physical, technical and economic terms [41-43], researchers aim at pointing out that, in the case of religious buildings, it is necessary to take into account additional specific criteria, 
that in most cases are not based on the best cost-benefit ratio, to combine the needs of preservation with those of the sustainable upgrading of a historic building [44,45].

Moreover, it is also necessary to consider constraints deriving from regulatory framework, the typological-dimensional characteristics and the historical-architectural ones, used to assess the compatibility of new uses according to standard and established criteria [44].

\section{Methodology Supported by Criteria of Contemporary Restoration}

During the last two centuries the ever-refined theories of restoration moved decidedly towards a critical approach, focusing on conserving the authenticity and the character of the building but at the same time, leaving space for quality, well-reasoned and recognizable modifications able to add valuable stratifications to our heritage [41-44].

The methodology developed for the present research moved from these consolidated assumptions (see Figure 1).

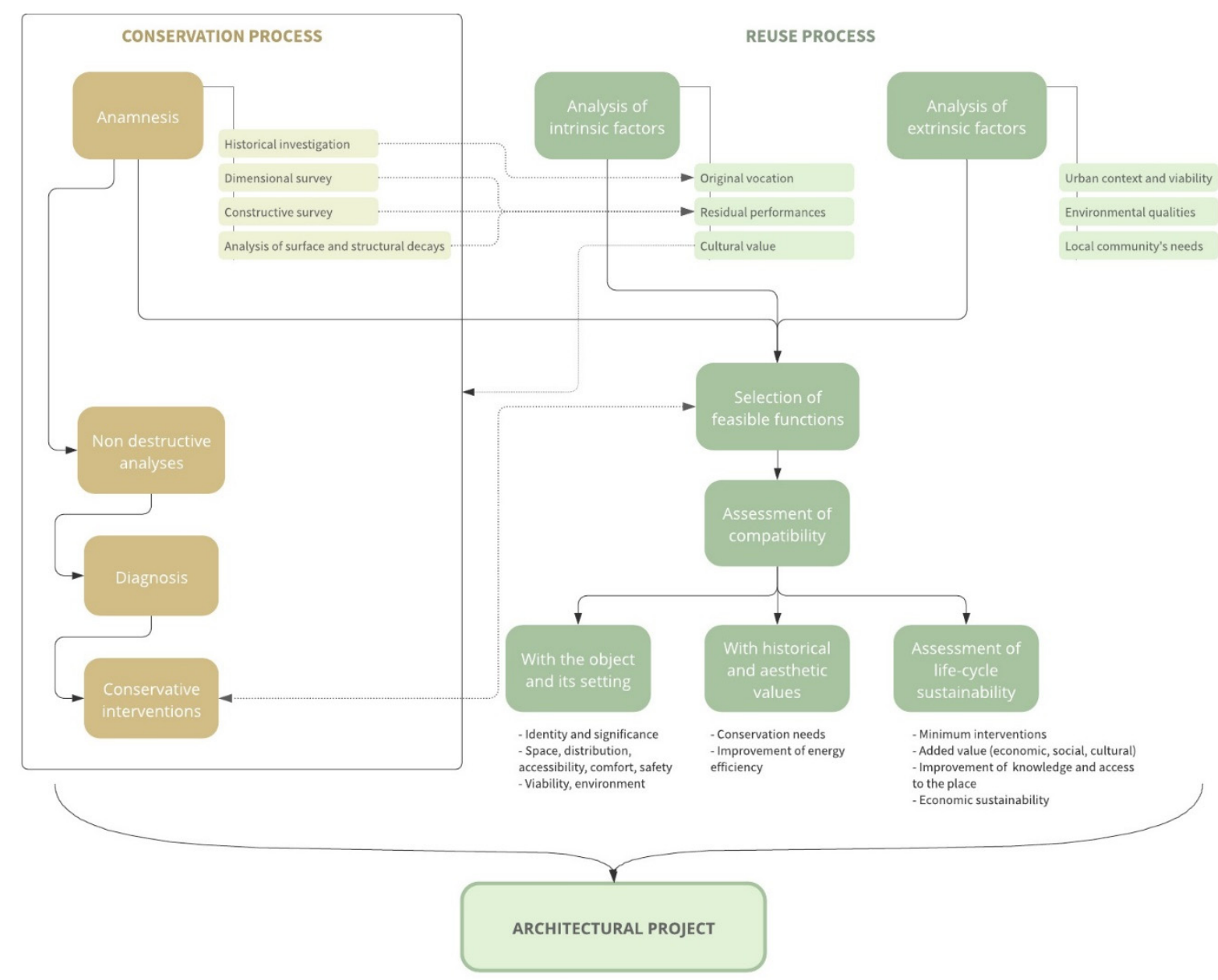

Figure 1. Conceptual framework of the methodology implemented in the research.

By combining two different phases, parallel and both underpinned by accurate knowledge of the building, an overarching architectural project is defined. The first route is focused on a survey of the material consistency of the building with the purpose of conserving and protecting the authenticity of materiality and construction techniques used. The second uses the result of the survey to evaluate and compare new possible functions to assess their compatibility and select the one that appears to be more sustainable and effective in exploiting the underestimated value of the heritage [45-47].

The Anamnesis represents the first step of the knowledge strategy, that consists in recollecting all the information-history, dimensions, constructive techniques and materials, 
conservation status, decays [48] — to be critically discretized, systematized and represented in order to support accurate levels of reading in the following steps.

During this phase particular attention has been paid to historical investigation, aiming at understanding the nature of the relationships established between by the object with its setting and the community, investigating whether they are ongoing or ceased and, in this case, why. In fact, as stated by Sangiorgio et al. [33] "urban context location is a determining factor for an artistic value in reference to the built environment" particularly when referred to religious heritage, which is often considered of greater value if it shows strong relationships with its surrounding urban context.

The second step is the diagnosis: in this research direct observation played a central role in producing the preliminary assumptions to be verified with instrumental analyses and define a plan of non-destructive analyses such as infrared thermography, sonic and ultrasonic methods, radiography and moisture measurements. In our research specific testing are advised to determine the scale of pathologies: drilling method for moisture analysis and cross-section, combined with XDR (X-ray powder diffraction) and XRF (X-ray fluorescence) to quantify the phenomena of soluble salts and black crust [49].

The information resulted from these phases underpinned the choice of the most appropriate actions, according to the criterion of minimum intervention as "the more fabric that is removed the less of the original building will remain, with a corresponding reduction in the cultural significance of the structure" [50,51].

At the same time, these data are taken into account in the phase of evaluation, in which the comparison between the residual performance and the possibilities and risks of the new functions drive the decision-making process.

On a first level of analysis, the peculiar typological constraints of the case studies pave the path for the hypotheses of receptive-related new uses. In fact, convents and monasteries are connotated by distinctive layout made up of numerous rooms connected with efficient distribution spaces, rhythmic presence of openings providing natural light to all the spaces, which make them flexible in regard to new uses.

Moreover, they have connections with places of interest in the territory, being them located in the city centre or in the countryside. Therefore, hypotheses of new uses that can benefit from these features, such as the ones abovementioned, are immediate.

Once the selection has been narrowed according to these premises, other considerations urge. It is worth noting that in the light of the ever-increasing complexity of regulations and constrains provided by the authorities involved in the protection of heritage-at all levels, local, regional and national-not all the possible new uses are implementable. That said, some of them have to be discarded in order to comply with allowed use and interventions on the heritage, avoiding the ones that would require major modifications or expansions.

Ultimately, as previously stated, in this research we wanted to focus on the role of heritage in promoting social sustainability: in order to do so, a high degree of preference has been granted to new uses that appeared to be more socially valuable in terms of increasing engagement among different communities and promoting positive social values.

As some studies have noted, heritage revitalization cannot achieve meaningful results if not incorporated in a broader strategy of fight against wealth/poverty gap. The concept of community itself encompasses complexity, diversities and fragilities. In the search for enhancing immaterial value to add to a healthy community, the question of inclusion is a key one, hence the need for community-based participation in the selection of new feasible functions, focused on fragile parts of the community and their specific need. Subsequently, the involvement of selected actors-such as public administrations, cultural and non-profit association - that in various forms are committed to address social inclusion is crucial in a more social oriented approach [51-54].

A similar approach is undertaken by other academics, that in various forms, stress the need for the diversification in the stakeholders' involvement. Rey Perez et al., for example, use information provided from three different approaches for the acknowledgement of the 
material and immaterial values of a place: the first level of information is the one provided by the administration in charge of managing and protecting the heritage, that will provide the necessary regulation and constrains to any intervention due on it. The second level is provided by a scientific pool of experts in various fields, such as geography, environment, anthropology, whose studies will deepen the knowledge of the heritage and the ability of evaluating it. The third level is provided by the citizenship, that in various ways are called to give their personal perception about what material or immaterial value needs to be protected [55].

In the light of the above, selected interlocutors have been interviewed, that are indirectly or directly involved in the management of the heritage, or represent relevant community groups, such as local administrations, public services, and non-profit association. This process had a fundamental role in detecting the needs that the community perceive as the most relevant, and therefore, addressing those needs in a renewed function seemed a key factor for restoring the engagement with the heritage and thus, conserving and transmitting its immaterial values.

\section{Case Studies: Opportunities of Reuse Exploiting the Franciscan Hospitality}

The abovementioned methodology has been applied to some case studies with the proposal of new uses for former ecclesiastical buildings. The cultural significance of these buildings lays particularly in their moral values and ethics, namely the Franciscan ideologies of charity, benevolence and selflessness. For the three case studies (one Capuchin and two Franciscan convents) this ideology has always been permeating the history of the buildings, despite of the transformations and different uses succeeded over time. Therefore, the proposed new functions aim at renewing these values and keep their memory alive.

\subsection{The Capuchin Convent of Villagonia (ME)}

In the medieval town of Taormina (NE Sicily), facing the Ionian Sea is the turn-of-thecentury convent of the Capuchin Friars of Villagonia (Figure 2).

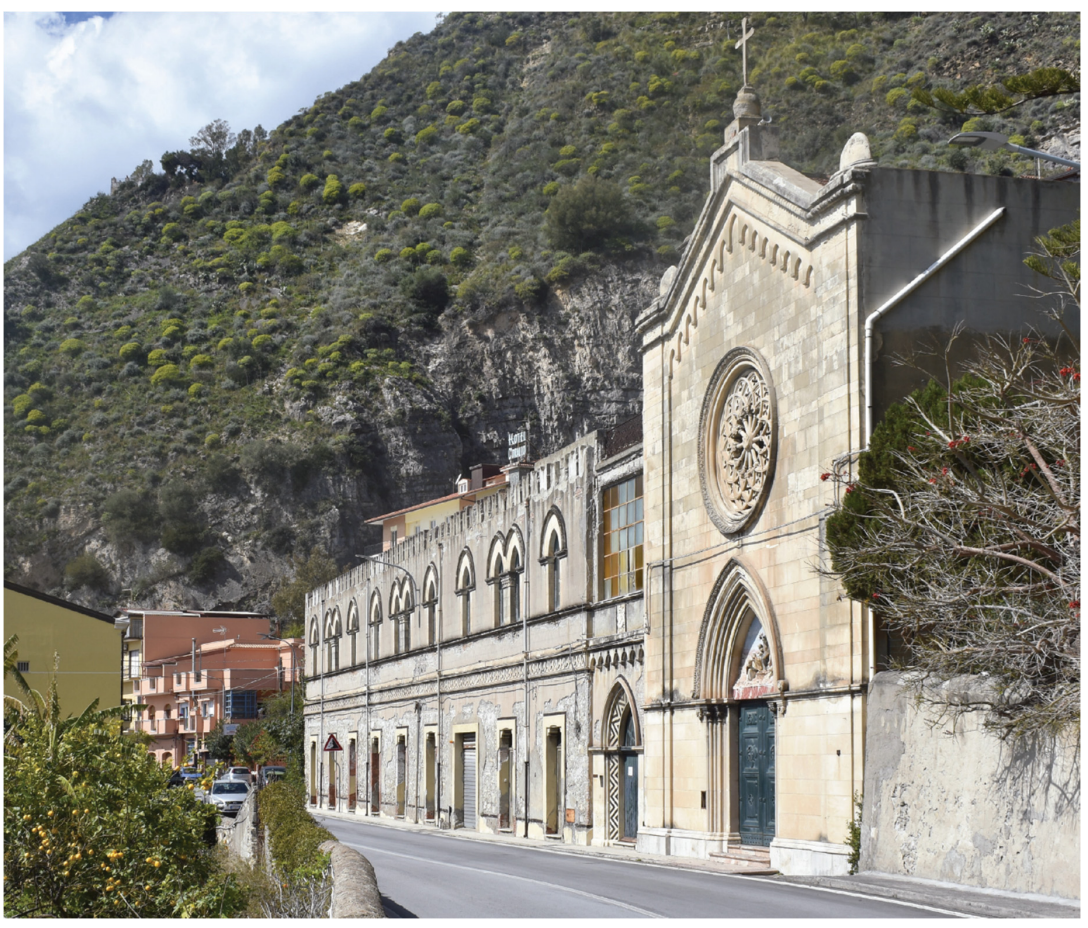

Figure 2. The Convent of Villagonia and the adjacent Church of Mother Mary of Pompei. With the main one facing the Ionian Sea, it is immersed in a remarkable landscape comprising of medieval built heritage and protected by regional regulations for the high environmental qualities. 
Lying adjacent to the Church of Mother Mary of Pompei and built between 1914 and 1926, it is rectangular-shaped and features an elegant mixture of Neo-Gothic and Neo-Romanesque architecture.

Its origin dates back to the late XIX century, when the Belgian businessman Gastone Lecomte settled in Sicily to start a business of lime production and built a small private chapel where the current church is. Years after, the Lecomte family donated the chapel and the adjacent single-storey building and the to the Capuchin Friars of Taormina, which they have assumed as their spiritual guidance and therefore were particularly close to. The Friars then transformed the building into their convent (1914-1915), and they built a larger church to replace the old one, as the growing community of the village started gathering in the former Lecomte chapel (1926) [56].

The simple yet elegant longitudinal development of the convent, not so common for a Capuchin Convent, is dictated by the distinctive orographic conformation of the landscape, with terraced steep hills arriving to just some steps from the coast. This setting brings the building to lean to the terrain, separated from it by an embankment, as shown in the sections (Figure 3).

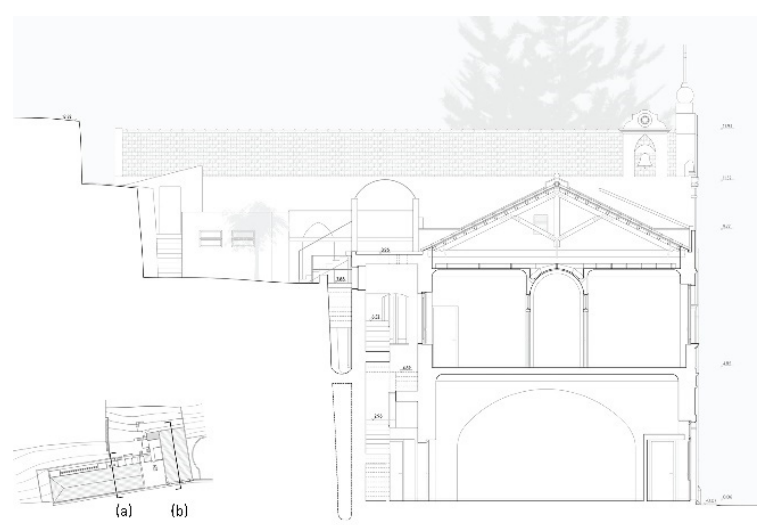

(a)

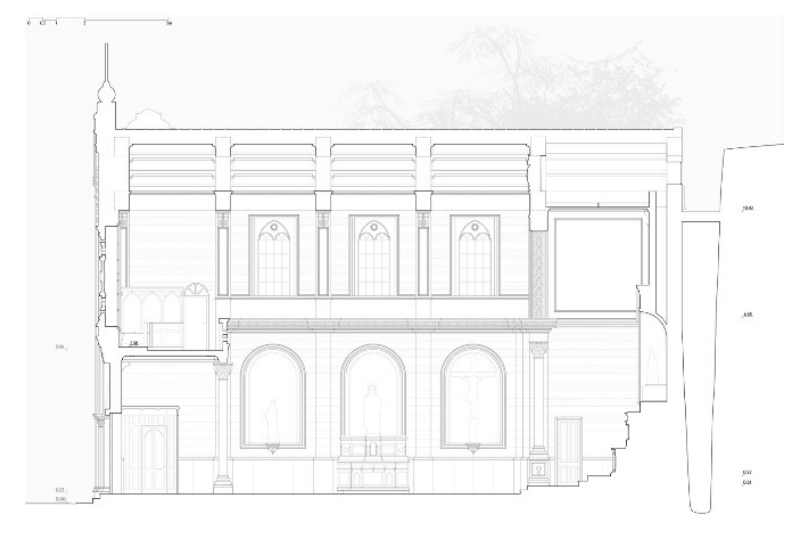

(b)

Figure 3. Sections of the convent (a) and the church (b) highlight the strong relationship with the landscape; the buildings are underground partially.

The back terraced hill provided the friars with a garden to cultivate for their own sustenance. The cavity between the building and the hill has been filled with enclosures to provide additional access to the ground floor spaces. This intervention, combined with other modifications and additions realized over the years, especially after the WW2 bombing, has proved damaging both for the visual appearance of the architectural ensemble and with regards to the hygienic conditions of the ground floor spaces, as resulted from the inspection of the interiors. The knowledge phase combined archival research with dimensional survey and careful visual observation and resulted in an accurate corpus documentorum of the conservation status. The result enabled us to detail the construction techniques used-from the rubble limestone masonry of the ground floor walls to the iron-framed intermediate floor and the timber truss roof made of chestnut wood-and the surface alterations affecting the interior and exterior materials. Among them, particular attention is due to erosions, efflorescences, honeycombing, which harm the legibility of the local limestone and basalt façade stonework; stain and biological colonization, apparently related to severe rising damp; diffuse cracks developing across the horizontal structures which should be further investigated to assess the presence of structural issues.

After assessing the residual performance of the building-including, but not limited to dimensional characteristics, openings, exposition, conservation status of surface materials and structures, conservative interventions required, modifications required to adapt the building to the new function—different hypothesis have been compared: a touristic 
accommodation, an elder house, a migrant shelter, and a shelter house for healthcare migrants. The first option has been selected because it is currently under consideration by a local association aiming at refurbishing the building, the second and the third ones were suggested as possible new uses by some of the members of the capuchin order (proprietors of the building) and locals who are continuous users of the church, while the third one was suggested by workers of the near hospital. All the options were judged able to benefit from the typological characteristics of the building, in terms of indoor and outdoor spaces and distribution, and therefore, would require limited modifications to the layout in order to be implemented. Moreover, they are compatible with local regulations that, despite being outdated, allows for receptive and commercial uses in the area. Despite the first option seemed to be the most economically sustainable, no objective value was found in terms of ability to provide beneficial social effects. The last three options, on the contrary, were judged more favourably because they promote a renovation of the immaterial value of the building, in relation to the capuchin's core values of assistance and hospitality and were therefore preferred as the overall value, not only economical but also social and cultural, would be greater. Nevertheless, further analyses (number and capacity of healthcare-related local facilities, interviews with the local administration) did not provide evidence of a strong need for an elder home, nor a migrant shelter in the area.

Other interviews with local workers, the hospital administration and representatives of a local association of child care, instead, brought light on the issue of healthcare migration, regarding disadvantaged people who travel to receive proper medical assistance in the nearby hospital in Taormina. Healthcare migration is an increasingly concerning phenomena creating in the subjected people the sense of losing their safety, namely their home [57], which adds to the concerns regarding their health. This phenomenon is perceived as particularly important in the local context, as a large number of families and chaperones travel long distances to support their loved ones that are being treated in the local hospital, often facing economic difficulties due to the strong touristic vocation of that territory. In fact, statistical data provided by the local health authority, confirmed that the two departments with the longest average stays, oncology and pediatric cardiology, host a great percentage - around a third — of patients coming from outside of the province [58]. This issue was therefore judged as a relevant local need, that urge to be addressed. The hypothesis of a health-care related facility proved to be the most suitable because: compared to the others, it offers a more valuable opportunity to address a need that is felt as particularly relevant by the local community and therefore it appears to be more effective in encouraging a new type of engagement with the heritage, promoting social interactions between people of different origins and renewing the role of hospitality once played by the Capuchin Friars, whose departure broke a profound bond with the community [49].

The project focused on providing the new users with two types of accommodation: one for a long-term stay and one for a shorter-term stay, so as to address the needs emerged from data provided by the hospital's administrative office about the average length of hospitalization [58]. Two crucial points have been addressed: on one side restoring the legibility of the original architectural shape was highly desirable, therefore the choice of removing the inconsistent additions built from the second half-century and replacing them with a new volume responding to a minimalistic and respectful architectural style, with the aim of improving access, quality of open spaces and increase natural light and ventilation (Figure 4); on the other side, the interior layout has been redesigned in order to host the new function focusing on accessibility, taking into account users with reduced mobility or perception disorders. To do so the plan remains as simple as possible, with minimized distribution spaces and strong visual connections between common areas in order to facilitate spontaneous spatial orientation and reducing confusing routes (Figure 5). At the same time, particular attention has been paid to offering the users the choice of having their privacy or using the common areas to socialize and find support by sharing their experiences. 


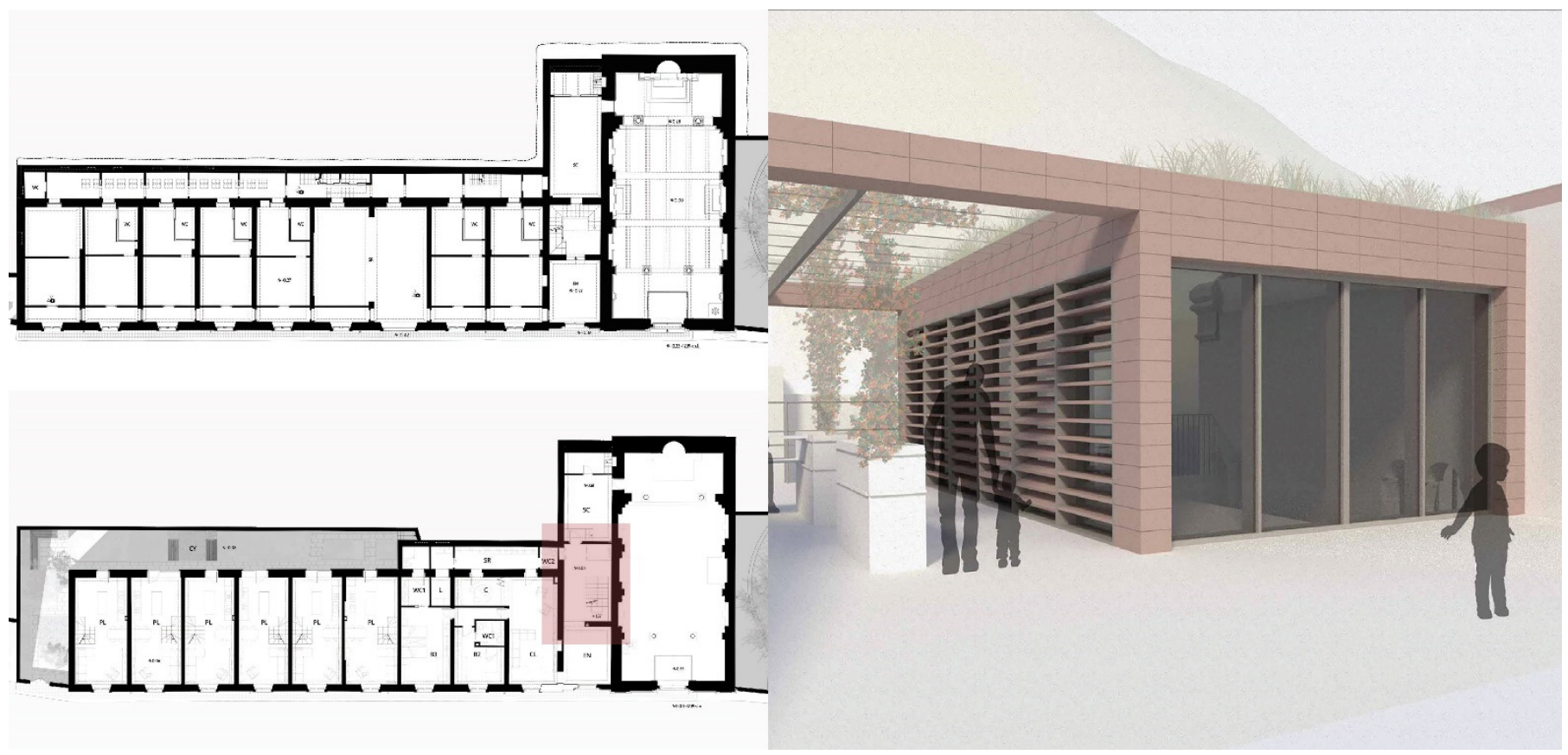

Figure 4. On the left the comparison between the current (above) and the proposed ground floor layout of the convent of Villagonia shows how minimum modifications are required in order to implement the new function. The render shows the new volume (highlighted in red) that reconnects the convent and the church providing new access and vertical connection up to the terrace.
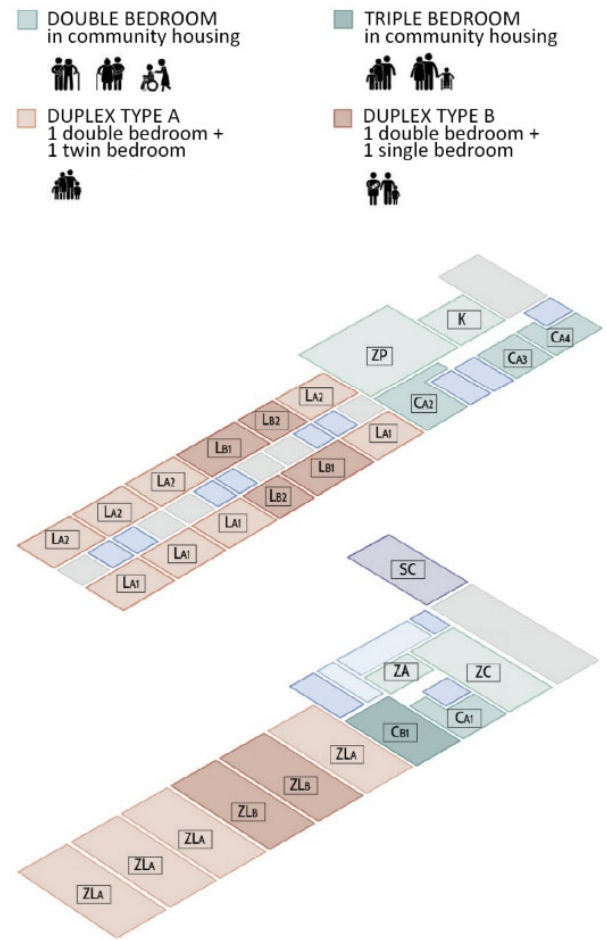

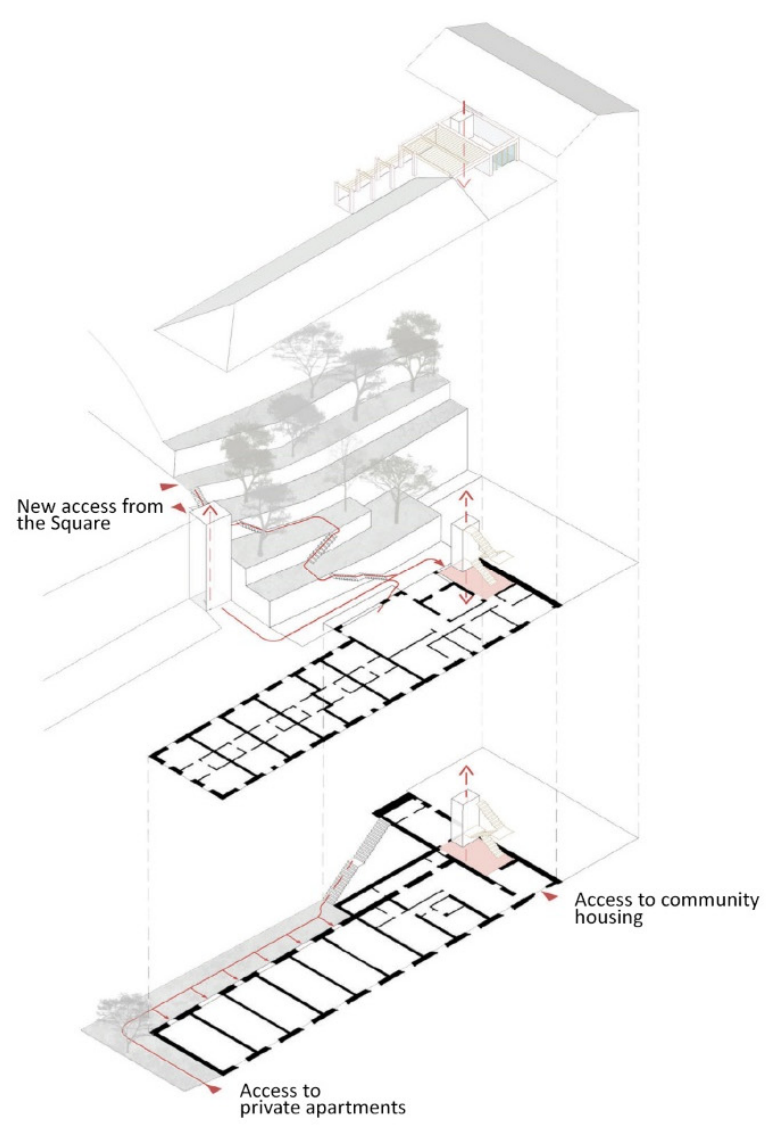

Figure 5. Diagrams of the new layout. 


\subsection{The Convent of the Friars Minor in Grammichele (CT)}

The Convent of the Minor Friars of Grammichele (Figure 6) was built at the end of the 18th century. Featuring a central courtyard, with stone pillars and rounded arcs, the building's layout was, as usual for monastic buildings, organized in two floors, where the ground floor hosted daily duties and routines, while the upper floor was used as a dorm. After 1866, when orders and religious corporations were suppressed, their assets were seized by the new-born Kingdom of Italy. The Convent of Grammichele was no exception and its government was given to the municipality who carried out demolitions and modifications to adapt it to host an elementary school for women.

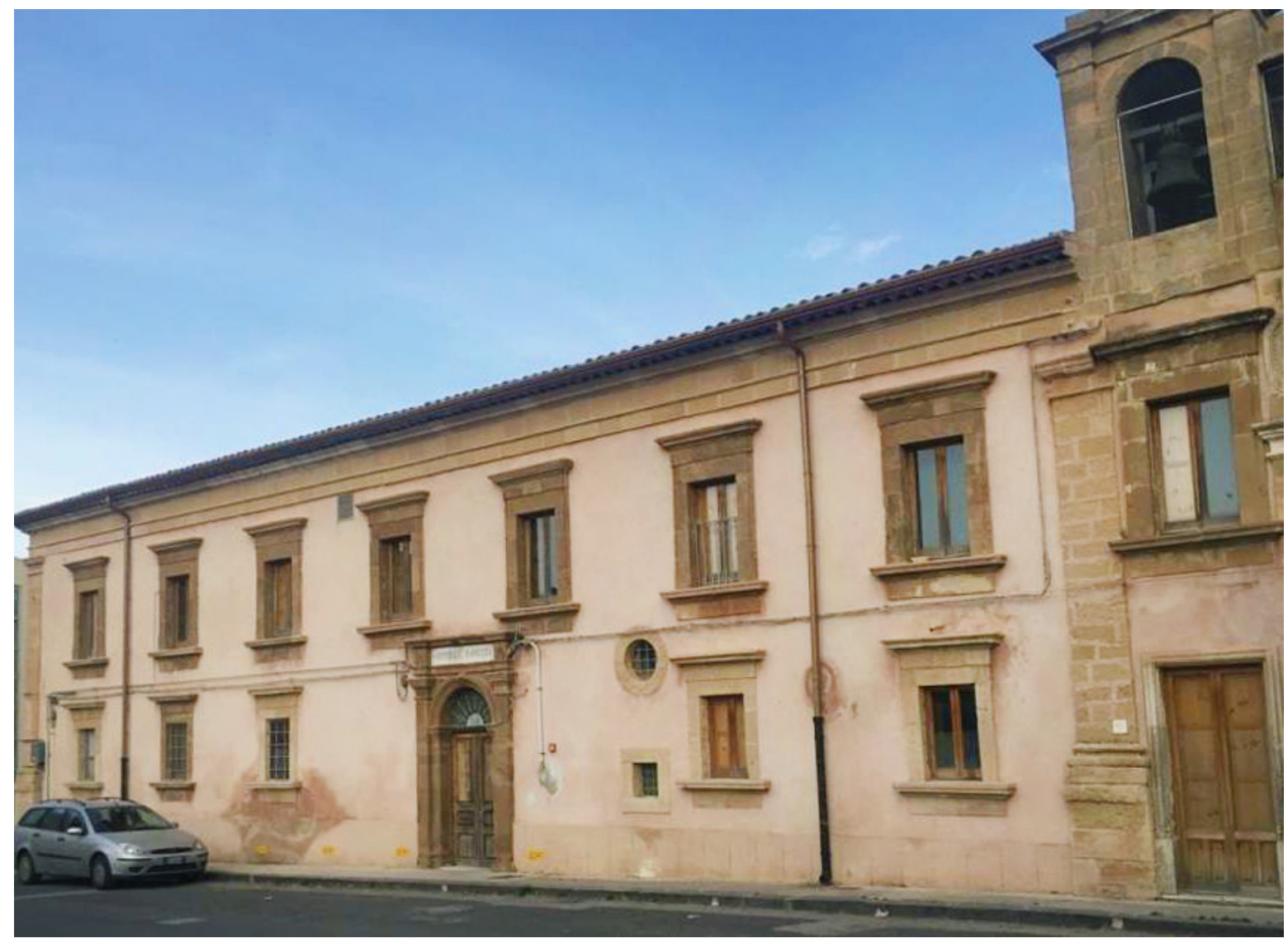

Figure 6. The main façade of the Convent of Friars Minor in Grammichele. The Church of the Holy Immaculate Mary is adjacent to it.

After being readapted again as a hospital (1904) the convent was added with a new element, now demolished (2009) and lays in disuse since 2006.

Particularly notable is the central cloister that enlightens the rooms distributed around it. The west internal front has been severely modified with arched windows enclosing the first-floor loggia.

The structural masonry, made of rubble local tuff stone is refined with renderings both in the exterior and interior facades, interrupted by decorated cornices and portals in local stone blocks. The most common degradations that the survey pointed out are related to rising damp: in fact, the lower portion of the masonry is in every front visibly wet and here have been detected efflorescence, biological patina and gaps in the render, often resolved with cement mortar patches. Additionally, the exposed stone blocks are often subjected to a general erosion. The accurate technological and degradation survey (Figure 7), however, pointed out that the general conservation status is good, due to the restoration works carried out in 2006 in the interiors and the roof and therefore, the building has strong 
residual potential and requires minimum conservative actions to reinforce its return to be used by the community.

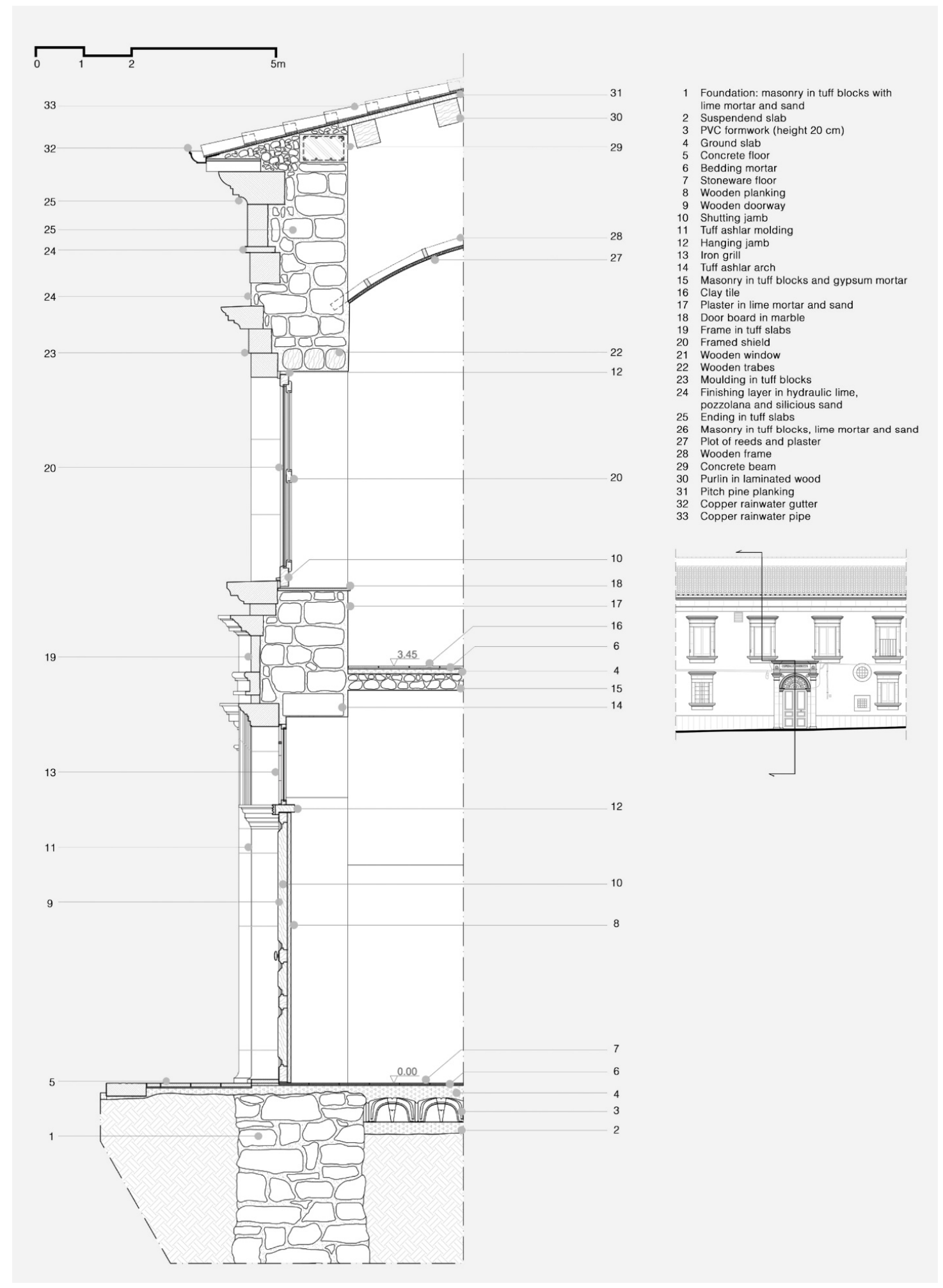

Figure 7. The survey of the technological apparatus highlighted the materials and used construction techniques. The detail shows the section of the building's stone masonry from the foundation to the traditional wooden roof. The residual performance of the building makes it able to support new uses following minimum interventions. 
The historical analysis pointed out that, regardless of the evolutions occurred to the building through the centuries, the leitmotif of its different uses has always been related to the care of people, and the Franciscan ideology of hospitality.

It was, therefore, natural to consider as hypotheses for the new use, those related to hospitality and, taking the suggestions of the local municipal administration and the needs emerged from the local news, the selected new possible uses were the reinstatement of the health-care facility and an elder house.

Although both hypotheses show good compatibility with the typological constraints (as proven by the fact that the first was already implemented in the beginning of the century), and with local planning regulations - the building is just outside the borders of the historic centre and is labelled as public services-further analyses allowed to deepen the process of comparison. Statistics about the local population highlighted progressive aging and a resulting increase in diseases and disabilities among the elders. The need for the care of people over 70 years of age in the area is high and constantly increasing, as we have known from the local municipality. Besides, data provided by the Provincial Health Authority allowed us to identify the most relevant health-care related needs in the area that are currently not met: for example, the number of beds according to elder healthcare is insufficient and there is the lack of first aid point, vaccination point and rehabilitation centre in the area.

Therefore, the most compatible new use has been detected in a mixed facility hosting an eldercare home and general healthcare services, aims at satisfying the interest of the community, while conserving and enhancing the memory of the building.

The first step of the intervention is the removal of the additions and modifications judged inconsistent because weakening the reading of the original architecture.

Then, the new layout has been arranged to host the services needed-first aid point, counselling centre, family doctor and vaccination point-on the ground floor and the eldercare home with 10 rooms and a rehabilitation room on the first floor (Figure 8).

The project looks towards a systematic integration in the network of eldercare facilities disseminated throughout the territory and the close towns, empowering and completing the service for the community, thus updating the actual formal and functional vocation of the building. Besides, it also looks at strengthening the added value of a conservation process in regards to employment creation, attraction of new intellectual capital and innovation [59].

\subsection{The Convent of San Francesco in Troina (CT)}

The Convent of San Francesco and the adjacent Church of the Immaculate lay in the heart of the medieval fortified town of Troina (NE Sicily). The convent was born in the second half of the 17th century over the rests of a Norman fortification, and it is arranged on two elevations developing around a central courtyard. The Franciscan friars who inhabited it distinguished themselves for being particularly cultured and therefore committed as keepers of the finest culture and teachers for the local community.

They lived in the convent until 1866, the year in which the new-born Italian state issued the national law of suppression of the religious orders, enabling it to acquire the religious assets belonging to ecclesiastical orders. The convent was then adapted to civil uses and divided between two different public proprietors; after hosting a range of different uses and activities, both cultural and economic, part of the building was converted into a male school and the rest hosted the municipal library until 2007.

The magnificent sandstone rubble masonry, exposed due to the lack of rendering, highlights the different stratifications of the building, ranging from the Norman tower and buttresses to neoclassical portals, witnessing the transformation implemented to adapt the complex to different uses over the centuries (Figure 9). The survey of the interiors pointed out remarkable construction techniques such as large brick barrel vaults and groin vaults often enriched with painted portions and gypsum mouldings, while the courtyard is punctuated by pilasters and round arches made of squared sandstone blocks. 

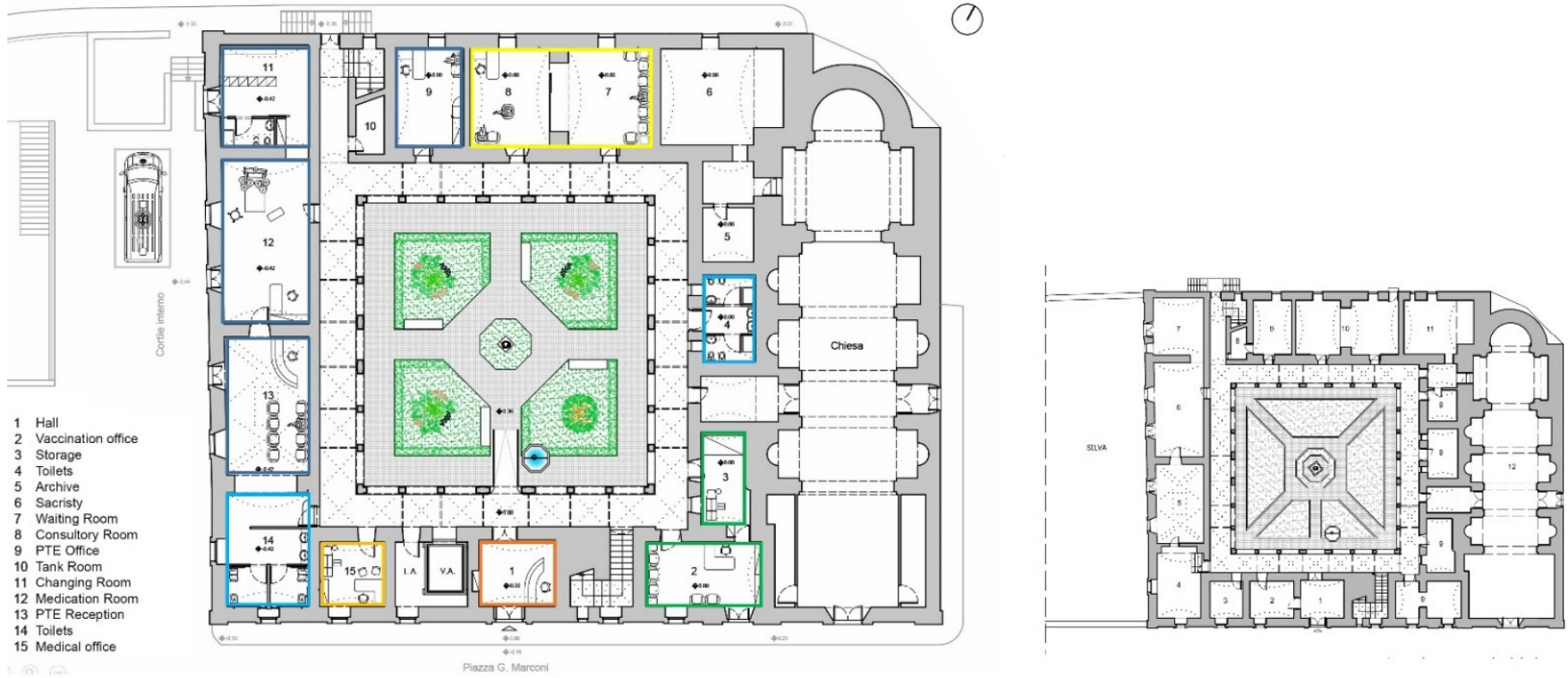

(a)
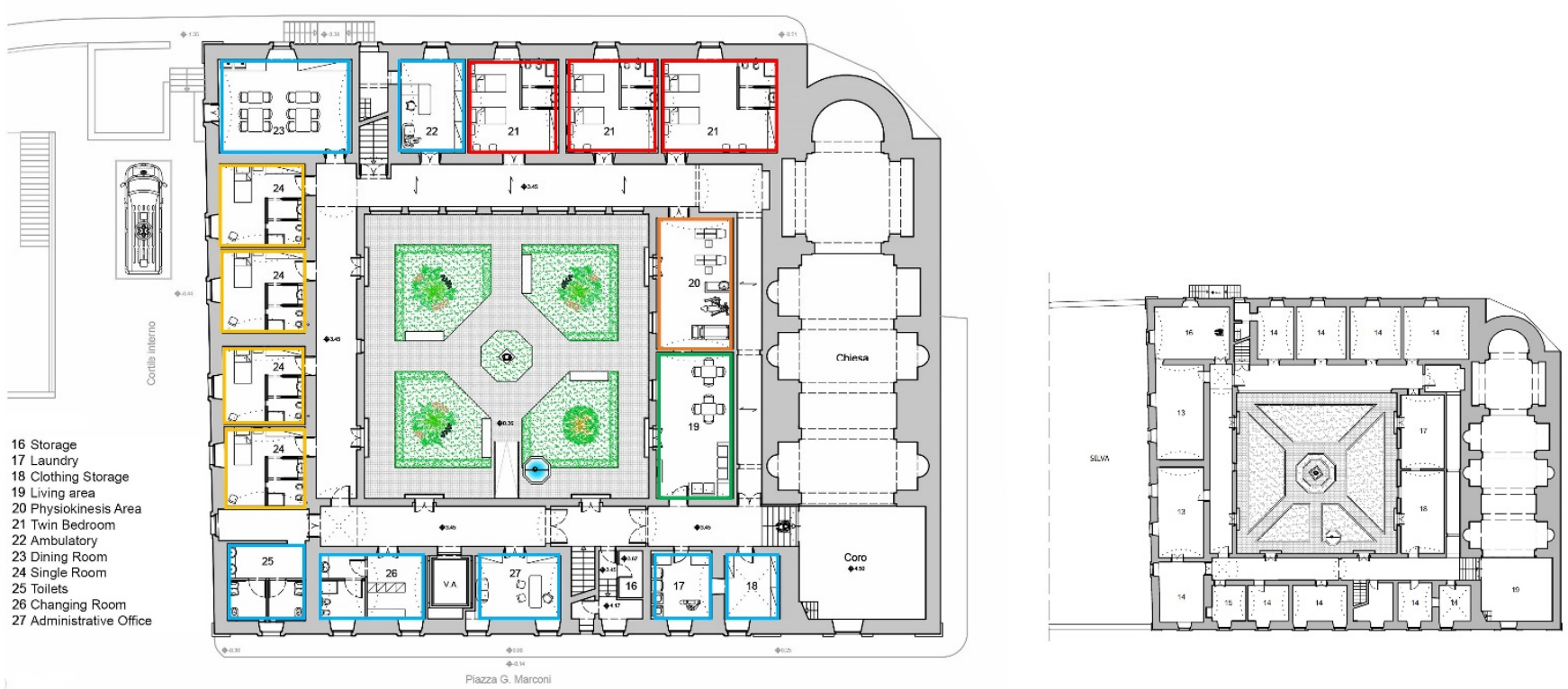

(b)

Figure 8. The project for the new layout of the Convent of Grammichele on the ground floor (a) and first floor (b). The project, responding to the criterion of minimal intervention aims at restoring the legibility of the original layout, removing only the inconsistent additions built over the last decades, visible in the current layout, on the right. 


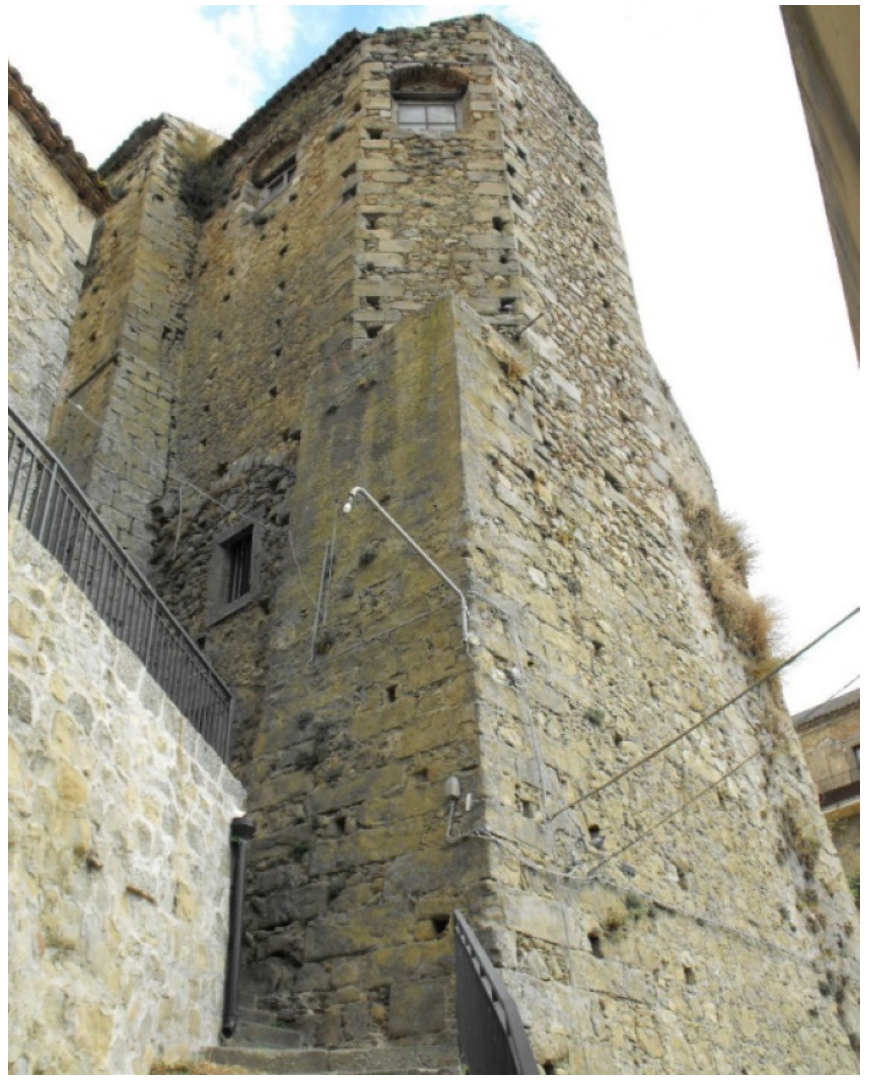

(a)
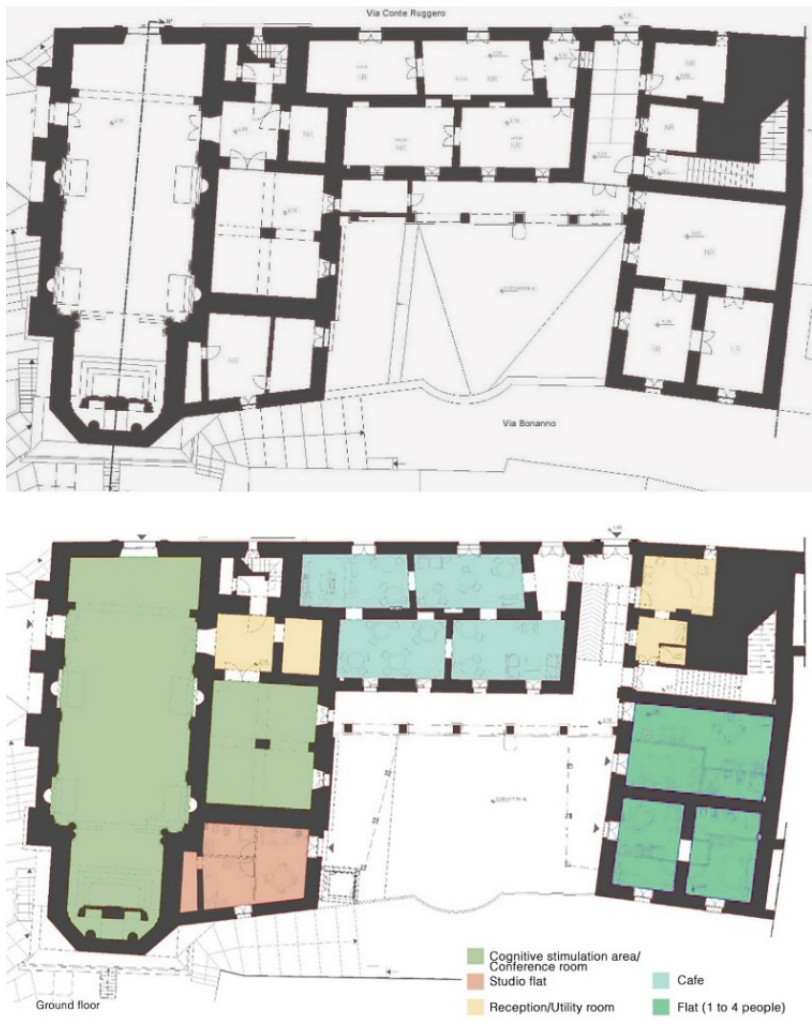

(b)

Figure 9. The basement of the Norman Tower (a) Convent of San Francesco shows the exposed rubble masonry characterizing the facades and the various architectural elements dating back to different periods. On the right, the ground floor of the complex (b) that will host a variety of functions in a layout that is minimally changed compared to the original one (above).

The prolonged disuse and lack of maintenance of the building resulted in severe degradation phenomena, especially in regard to the exterior and the interior surfaces. The exterior masonry is subject to widespread erosion and biological colonization while the interiors are characterized by the effects of generally diffused rising damp. The detected degradations call for immediate conservation interventions which were decided according to the most minimal and respectful approach; therefore, consolidating and cleaning the deteriorated materials was nearly always preferred over removal, demolition and substitution, in order to better preserve the character of the building.

Preliminarily to the choice of the new function, careful analyses of the context were carried out, ease and modes of access, distance from places of interest, environmental features - exposition, ventilation climate, pollution-together with the characteristic of the building itself-dimensions, presence of relevant service areas, fire escape, water and electrical systems (Table 1).

Table 1. The table shows how most of the patients come from outside the town of Troina to receive medical assistance in the local medical facilities. Data provided by IRCCS Oasis Holy Mary (2017).

\begin{tabular}{ccc}
\hline & \multicolumn{2}{c}{ Distance of Patients' Place of Origin } \\
\cline { 2 - 3 } & $\mathbf{0 - 7 0 ~} \mathbf{~ k m}$ & $>\mathbf{7 0 ~} \mathbf{~ k m}$ \\
\hline Ordinary hospitalisation & 312 & 1061 \\
Day hospitalisation & 557 & 743 \\
\hline
\end{tabular}


The building is owned by IPAB (a religious institute for social assistance) and managed by the local municipality. Both institutions have as a priority the conservation of the building, which lays in disuse since the early 2000s, but so far failed to do so due to scarcity of funds. The hypothesis evaluated as new uses were a public library, a tourist accommodation facility, and an accommodation for healthcare migrants. The first hypothesis was suggested by the previous use. Despite it shows a strong compatibility in terms of layout and a good compatibility with the history and significance of the building (the capuchins were teachers and keepers of the culture) the proposal is deemed not sufficiently sustainable by the municipality, who preferred to transfer the library in another location, closer to the municipal archives. In regards of the second and third option, interviews were conducted with the local municipality, locals and representatives of some of the main public facilities present in the area. The interviews pointed out that improving an active role of the historic centre in the life of the town is one of the most requested features by the local administration when restoring or refurbish a local building, addressing the ever-increasing issue of depopulation of its historic centre, despite it is full of valuable architectural heritage of Norman memory.

On the other hand, it emerged that the importance of the town of Troina lays in its pivotal role in the healthcare sector, enlightened by the presence of several healthcarerelated facilities operating in prevention, diagnosis, and rehabilitation, as emerged from the analyses carried out about the presence and types of public facilities in the area. These facilities host flows of patients with their families, create local employment in sectors directly and indirectly related to the healthcare service, but, more importantly, create added value by attracting skilled workers in the increasing sector of services collateral to hospitalization [60] such as rehabilitation and psychological support.

Therefore, this sector is clearly what makes the town stand out in comparison to other similar towns in the inland Sicily.

That said the result of the comparison was that both the remaining options suited the typological constrains requiring minimum modifications and no volume additions to be implemented; they were in line with the local and national planning regulation - the building is listed according to the national Italian law n. 42. 22.01.2004; they were judged able to provide income thus strengthening their economical sustainability. Ultimately the benefits in terms of social sustainability were judged higher in the case of the accommodation for healthcare migrants.

In fact, the proposal is thought for encouraging social engagement between people belonging to different communities and strengthening bonds between the hosted families and the hosting community, perceived as caring for their loved ones. That characteristic was believed to be more suitable for incorporating the principles of social sustainability and transmitting to future generations the value of hospitality towards disadvantaged people that the convent has been representing for many centuries.

A SWOT analysis finally pointed out how the Convent of San Francesco is an underestimate asset that can effectively contribute to the objectives of improving the quality of life in the society and renewing the perception of the built heritage as a central part of culture and identity of the local context (Table 2). 
Table 2. SWOT analyses supported the decision-making process about the new use for the abandoned building.

\begin{tabular}{|c|c|c|}
\hline & Strengths & Weaknesses \\
\hline Internal Factors & $\begin{array}{l}\text { Valorisation and reuse of architectural resources, } \\
\text { witnessing values of Franciscan hospitality. } \\
\text { Strengthening of the role of hospitality of the } \\
\text { historic centre. } \\
\text { - } \\
\text { Edressing the demand of short-term touristic stay. } \\
\text { Encourage relationships between users with } \\
\text { similar experiences. } \\
\text { Provide shelter and consolation to disadvantaged } \\
\text { users, who are forcedly far from their home. } \\
\text { Closeness and good linkage with local healthcare } \\
\text { facilities, offering additional services. }\end{array}$ & $\begin{array}{l}\text { - Weak performances of the technological } \\
\text { systems in meeting current technical } \\
\text { standards of indoor comfort. } \\
\text { Limitations to autonomous travel by car. }\end{array}$ \\
\hline External Factors & $\begin{array}{l}\text { Promoting the valorisation of public facilities } \\
\text { otherwise fated to oblivion. } \\
\text { - Creation of new places of aggregation, fighting } \\
\text { processes of social isolation and marginalisation } \\
\text { - Creation of locally rooted jobs. } \\
\text { Incrementing healthcare-related tourism posing the } \\
\text { bases for future development of cultural tourism. } \\
\text { Offer the chance to experience new places in the } \\
\text { town and encouraging the social cohesion with } \\
\text { local community. }\end{array}$ & $\begin{array}{l}\text { - Limited economic resources of public } \\
\text { administration } \\
\text { - } \quad \text { Standardization of interventions. }\end{array}$ \\
\hline
\end{tabular}

The project involves the rearrangement of the plan with three studio flats and seven shared flats, in which the strong separation between the use of the spaces allows users to choose between privacy and community life. Particular attention has been paid to encourage interactions with the local community and raise awareness on the theme of degenerative diseases, among the most treated in the local healthcare facilities.

The presence of collateral activities-family training and psychological supportcurrently carried out in the adjacent church proves the need for proper spaces to support the local healthcare sector. With this aim, specific areas dedicated to healthcare-related collateral activities have been designed to be used by all the community, including a new rearrangement of the interior of the church to host meetings and seminaries. The aim is to propel the systematization of such activities in order to increase the value of the service provided and address the objectives of the humanization of healthcare [60].

A modern addition to the ancient bell tower, which had collapsed partially, wants to use a contemporary architectural language, responding to the criteria of recognizability of the interventions, to the purpose of restoring the memory of the original building, projecting it as a new landmark for the town [61] (Figures 10 and 11). 


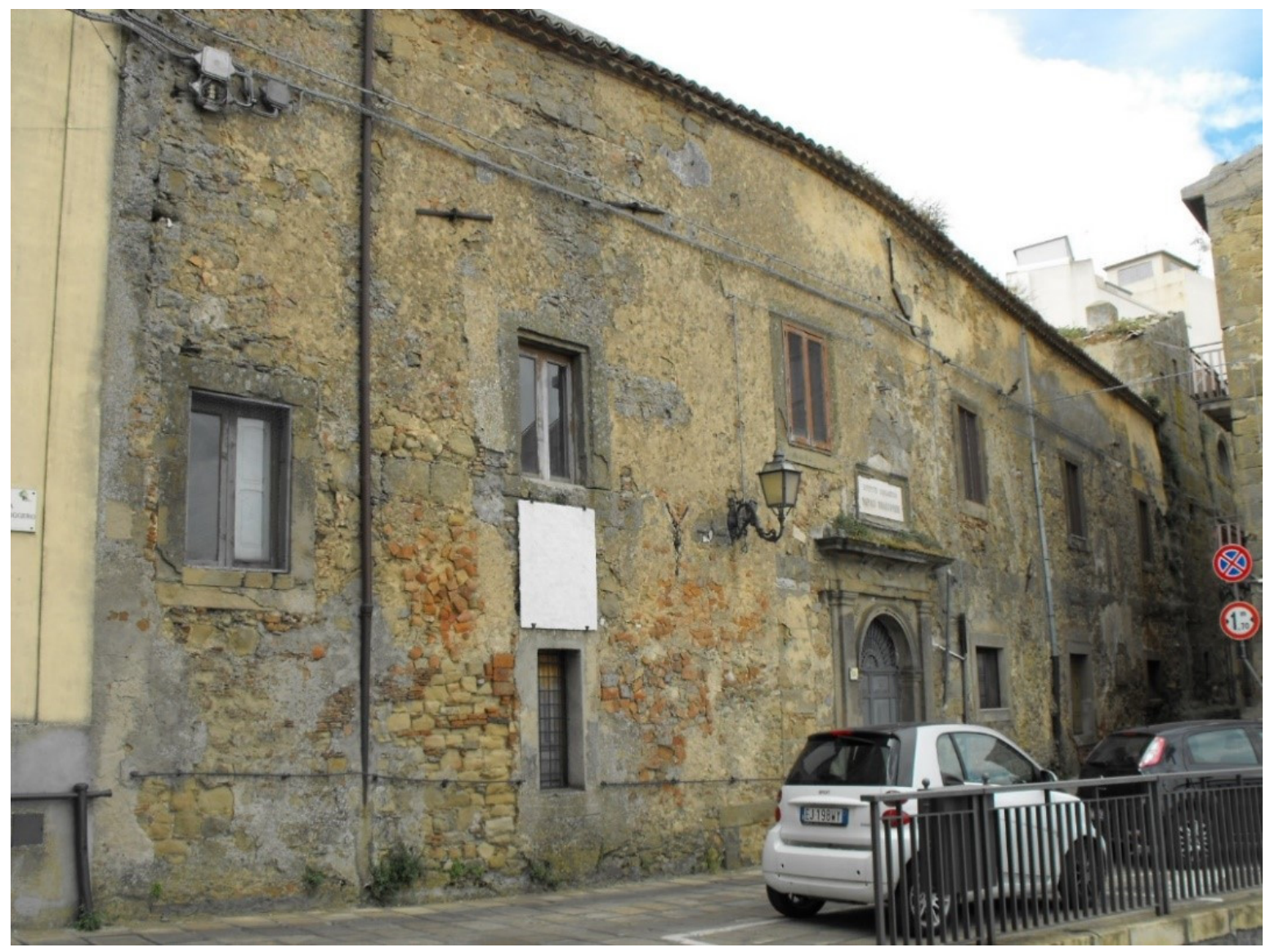

(a)

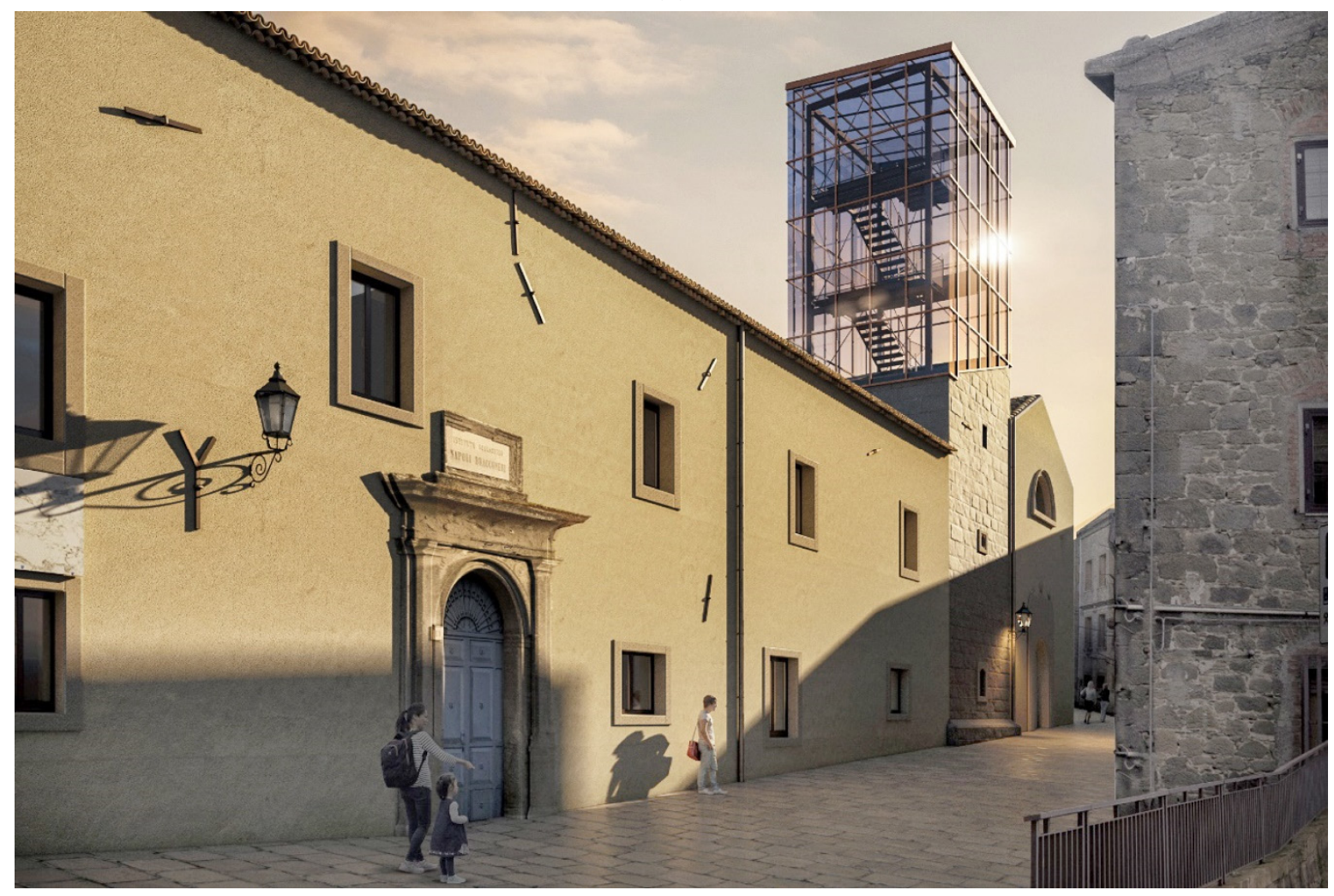

(b)

Figure 10. The current north façade with the ancient bell tower (a) and a render of the restoration project (b). 


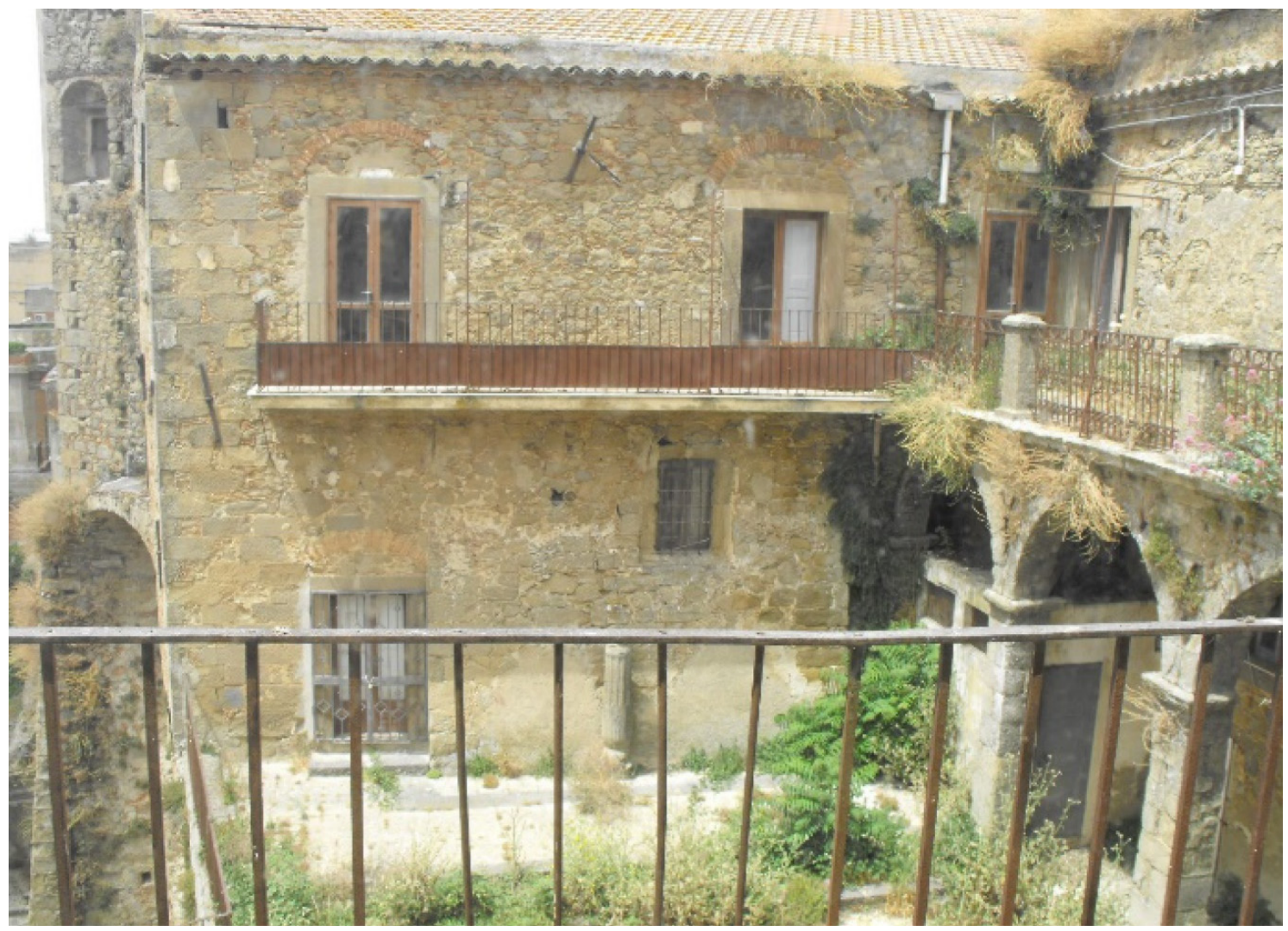

(a)

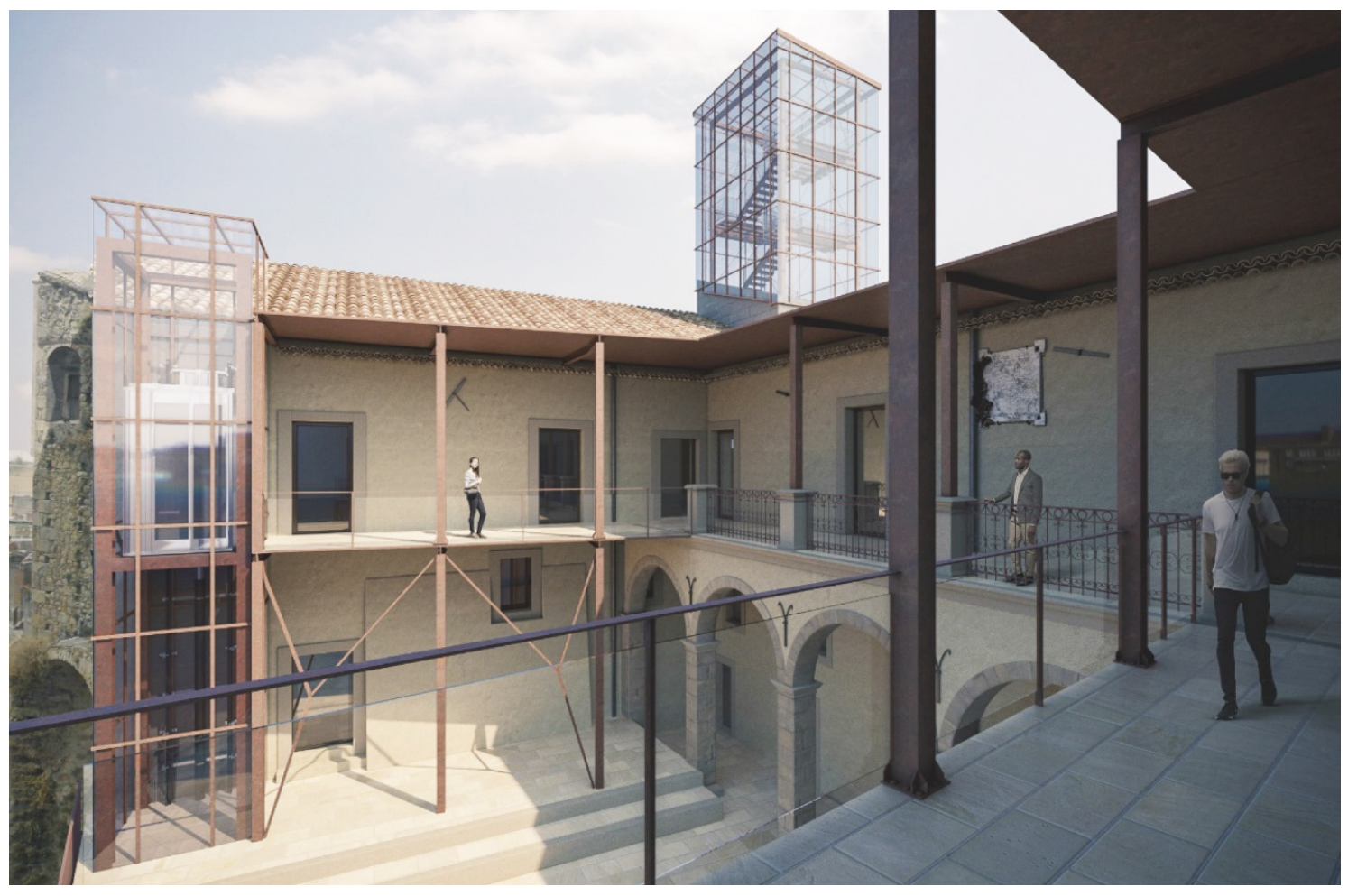

(b)

Figure 11. The current courtyard (a) and render of the restoration project with the contemporary additions (b). 


\section{Conclusions}

Our built heritage is the keeper of shared value and mute witness of the past. As shown, this heritage is threatened by abandonment because, despite a large number of policies and charters raising the awareness and sensibility towards it, its preservation still faces many difficulties which are firstly due to economic factors and unpreparedness of the management sector.

Although a religious places register increasing demand for access, proving their outstanding value is widely recognized, they can be considered as a burden when unable to generate economical profit and consequently, they are often left to oblivion. This risk affects both the material conservation-relating to the building itself and the historical and aesthetic heritage it keeps-and the immaterial values it represents.

All of these considerations pose a great challenge because the need for conserving these buildings must meet the needs of the new uses implicating a more complex and different kind of consumption.

In this scenario, good conservation practices are called to implement a holistic and transdisciplinary approach, not limited to the physical restoration, but aiming at catching and exploiting the unexpressed value that could stimulate quality and healthy processes of regeneration of the contemporary city [62].

As stated by the EU Commission, the conservation sector is already looking towards "new approaches focused on making [the heritage] fully part of the local community. Sites are given a second life and meaning that speak to contemporary needs and concerns" [3].

Moreover, many scholars are developing numerous case studies and methodologies $[9,10,19,20,28-30,32-37,41-43]$ to support appropriate adaptation strategies and some common key points can be identified in the most successful experiences: on one side, the acknowledgement and protection of the intangible value that do not cease to exist when the original use is dismissed [63,64]; on the other side, the participation, in the decision-making process, of experts from various disciplines-communication, economy, law-and, particularly, associations representing local communities and their most fragile sectors [65] with a view to a more inclusive action able to "initiate processes rather than possess spaces" [63,65].

The conservation project is nevertheless underpinned by necessary knowledge analyses that pose fundamental bases to the appropriate transformation strategy.

The research proposed a methodologically defined route: in the first phase, in-depth research on historical sources has been conducted to achieve a proper knowledge of the building, its construction phases and have an overview of the materials and technique used in the referred historical period and place; in the following phase an analysis of the conservation status has been carried out, based on qualitative and quantitative information, in order to establish what are the strengths and the weaknesses of the building and what interventions may be necessary to improve its performance; in the third phase, an assessment on the advantages and disadvantages of possible new uses is carried out in which the options are compared to the characteristics of the building, both regarding the conservation status and its values. Ultimately, the chosen new use is proposed through a compatible reuse project.

The presented case studies apply the aforementioned methodology and show how religious heritage has outstanding potentials and the application of consistent practices address not only the mere physical conservation but may also have positive impacts on the well-being of the community. Taking into account particularly relevant local needs while enhancing the values of our built heritage is a great challenge but also a great opportunity to move towards a broader view of sustainable development, as is continuously advised also in recent international policies [15,21,22,24].

One of the strengths of our case studies is that they have great potential not only in immaterial but also in material terms. Buildings such as convents, monasteries and others collateral to churches generally have distinctive layouts, deriving from consolidated modes of building, with considerable extension and a large number of rooms connected 
with effective distribution spaces. They often feature cloisters or gardens providing the beneficial effects of green spaces, high-quality constructive techniques and can potentially reach high standards of exposition, natural lighting and ventilation, in order to comply with the requirements imposed by current technical standards. In our case studies, that responded to the abovementioned qualities, the detected conservation status was such as to determine that they required minimum interventions to be adapted to new collective uses. Additionally, they have strong physical relationships with the built environment, in terms of accessibility, connections to close places of interest, and are embedded in the historic cores of their town. This can be a key factor for them to become the core of a network of facilities providing social healthcare-related benefits for the community, in this case.

A side note is that not all the religious heritage to be reused is in this state, and more invasive interventions may be required, resulting in a higher impact on the cost-benefit aspect. On the other side, more isolated buildings may have more difficulties in generating engagement and participation in the local communities.

Further developments of the research are individuated in examining additional and manifold case studies and implementing a methodology to assess whether, starting from very different conditions, with minimum interventions and appropriate reuse options, it is possible to address benefits for the community while preserving the values of the building, and achieve the sustainability of the action.

Author Contributions: Conceptualization, A.L.F. and A.M.; investigation, A.L.F. and A.M.; methodology, A.L.F.; supervision, A.L.F.; writing—original draft, A.M.; writing—review and editing, A.L.F. All authors have read and agreed to the published version of the manuscript.

Funding: This research was funded by the project "Strategies for Religious Heritage (StReH)" DICAR 2021-23 and the project "NEWS-Nearshore Hazard Monitoring and Early Warning System" INTERREG V-A Italia Malta 2014-2020 Asse prioritario III, Obiettivo Specifico 3.2 Codice C1-3.2-60.

Institutional Review Board Statement: Not applicable.

Informed Consent Statement: Not applicable.

Data Availability Statement: This study not report data from archived datasets.

Conflicts of Interest: The authors declare no conflict of interest.

\section{References}

1. Commission for Cultural Heritage of the Church, Lettera Circolare Sulla Necessità E Urgenza Dell'inventariazione e Catalogazione dei beni Culturali della Chiesa. 8 December 1999. Available online: https://www.vatican.va/roman_curia/pontifical_ commissions /pcchc/documents/rc_com_pcchc_19991208_catalogazione-beni-culturali_it.html (accessed on 25 March 2021).

2. Alexandrakis, G.; Manasakis, C.; Kampanis, N.A. Economic and Societal Impacts on Cultural Heritage Sites, Resulting from Natural Effects and Climate Change. Heritage 2019, 2, 279-305. [CrossRef]

3. Communication from the Commission to the European Parliament, the Council, the European Economic and Social Committee and the Committee of the Regions. Towards an Integrated Approach to Cultural Heritage for Europe. Available online: https: / / ec.europa.eu/assets/eac/culture/library/publications/2014-heritage-communication_en.pdf (accessed on 25 October 2020).

4. UNESCO. MAB Strategy 2015-2025; UNESCO: Paris, France, 2016.

5. UNESCO. Initiative on Heritage of Religious Interest. Available online: https://whc.unesco.org/en/religious-sacred-heritage/ (accessed on 25 October 2020).

6. Stovel, H. Introduction. In Conservation of Living Religious Heritage, Proceedings of the 2003 ICCROM Forum on "Living Religious Heritage: Conserving the Sacred", Rome, Italy, 20-22 October 2003; ICCROM: Rome, Italy, 2005.

7. Future for Religious Heritage (FRH) 2019 Annual Report. Available online: https://www.frh-europe.org/cms/wp-content/ uploads/2020/07/FRH-Annual-Report_2019.pdf (accessed on 25 October 2020).

8. European Construction Industry Federation (FIEC) 2019 Statistical Report. Available online: https: / fiec-statistical-report.eu / ocument-union (accessed on 25 October 2020).

9. Tamma, M.; Sartori, R. Religious heritage: Sharing and integrating values, fruition, resources, responsibilities. In Sapere l'Europa, Sapere d'Europa; Pinton, S., Zagato, L., Eds.; Università Ca' Foscari: Venice, Italy, 2017; Volume 4, pp. 557-572. [CrossRef]

10. Lindblad, H.; Lögfren, E. Religious Building in Transition; Greenhow, I., Translator; University of Gothenburg: Gothenburg, Sweden, 2018; pp. 5-18.

11. Plevoets, B.; Prina, D. Introduction. In Proceedings of the 5th EAAE Workshop: Conservation/Adaptation, Keeping Alive the Spirit of the Place, Adaptive Reuse of Heritage with Symbolic Value, Liège-Hasselt, Belgium, 13-16 October 2015. 
12. Study Shows That Secular Europe Backs Religious Heritage! Available online: https://www.frh-europe.org/eu-poll-result/ (accessed on 25 October 2020).

13. National Kyiv-Pechersk Historical and Cultural Preserve. Kyiv Statement on the protection of religious properties within the framework of the world heritage convention. In Proceedings of the International Seminar: The Role of Religious Communities in the Management of World Heritage Properties, Kyiv, Ukraine, 5 November 2010.

14. Committee on Culture and Education of the European Parliament. Report: Towards an Integrated Approach to Cultural Heritage for Europe. 2015. Available online: https:/ / www.europarl.europa.eu/doceo/document/TA-8-2015-0293_EN.html (accessed on 25 March 2021).

15. Architects' Council of Europe. Leeuwarden declaration-Adaptive re-use of the built heritage: Preserving and enhancing the values of our built heritage for future generations. In Proceedings of the Public Conference: Adaptive Re-Use and Transition of the Built Heritage, Leeuwarden, The Netherlands, 23 November 2018.

16. Committee of Ecclesiastical Entities and Assets of the Italian Bishops' Conference. Protection and Conservation of the Historical and Artistic Heritage of the Church; Norms of the Italian Episcopate: Rome, Italy, 1974.

17. Committee of Ecclesiastical Entities and Assets of the Italian Bishops' Conference. Le Chiese non più Utilizzate per il Culto, Rome, Italy. 4 October 2012. Available online: http:/ /www.diocesisalerno.it/wp-content/uploads/2012/02/documento-ceichiese-non-utilizzate.pdf (accessed on 25 October 2020).

18. Pontifical Council for Culture. Decommissioning and Ecclesial Reuse of Churches-Guidelines. In Proceedings of the Conference: Doesn't God Dwell Here Anymore, Rome, Italy, 29-30 November 2018.

19. Mork, M.I. Alternative Uses for Redundant Churches. 2015. Available online: https://www.researchgate.net/publication/279191 086_Alternative_uses_for_redundant_churches (accessed on 25 October 2020).

20. Foster, G. Circular economy strategies for adaptive reuse of cultural heritage buildings to reduce environmental impact. Resour. Conserv. Reclicling 2019, 152, 104507. [CrossRef]

21. UN General Assembly. Transforming our World: The 2030 Agenda for Sustainable Development. 21 October 2015. Available online: https: / / www.refworld.org/docid/57b6e3e44.html (accessed on 25 October 2020).

22. General Assembly of State Parties. Policy document for the integration of a sustainable development perspective into the processes of the world heritage convention. In Proceedings of the Policy Adopted on the 20th Session of the General Conference of UNESCO, Paris, France, 18-20 November 2015.

23. McKenzie, S. Social sustainability: Towards some definitions. In Hawke Research Institute Working Paper Series; University of South Australia: Magill, Australia, 2004; p. 18.

24. Icomos, A. The Burra Charter: The Australia ICOMOS Charter for Places of Cultural Significance; Australia ICOMOS Incorporated: Burwood, Australia, 2013.

25. Soini, K.; Dessein, J. Culture-Sustainability Relation: Towards a Conceptual Framework. Sustainability 2016, 8, 167. [CrossRef]

26. The Hangzhou Declaration Placing Culture at the Heart of Sustainable Development Policies. Available online: http:/ / www.unesco. org/new/fileadmin/MULTIMEDIA/HQ/CLT/images/FinalHangzhouDeclaration20130517.pdf (accessed on 25 October 2020).

27. Oren, G. Meta-Theming: A Tool for Heritage Site Management. Available online: https:/ /www.frh-europe.org/meta-theming-atool-for-heritage-site-management/ (accessed on 25 October 2020).

28. Velthuis, K.; Spennemann, D.H. The Future of Defunct Religious Buildings: Dutch Approaches to Their Adaptive Re-use. Cult. Trends 2007, 16, 43-66. [CrossRef]

29. Martins, A.M.T.; Cano, M.T.P.; Adell, E.M. Monastic Buildings: A Review about New Uses on Former Monasteries. The Portuguese Cistercian Case. IOP Conf. Ser. Mater. Sci. Eng. 2019, 471, 082037. [CrossRef]

30. Plevoets, B.; Van Cleempoel, K. Adaptive Reuse of the Built Heritage Concepts and Cases of an Emerging Discipline; Routledge: London, UK, 2019.

31. Šekularac, N.; Ivanović-Šekularac, J.; Petrovski, A.; Macut, N.; Radojević, M. Restoration of a Historic Building in order to Improve Energy Efficiency and Energy Saving-Case Study—The Dining Room within the Žiča Monastery Property. Sustainability 2020, 12, 6271. [CrossRef]

32. Abad-Segura, E.; Fuente, A.B.; González-Zamar, M.-D.; Belmonte-Ureña, L.J. Effects of Circular Economy Policies on the Environment and Sustainable Growth: Worldwide Research. Sustainability 2020, 12, 5792. [CrossRef]

33. Sangiorgio, V.; Uva, G.; Ruggieri, S.; Adam, J.M. Calibration of seismic vulnerability index for masonry churches based on AHP including architectural and artistic assets. In Proceedings of the 3rd International Conference on Recent Advances in Nonlinear Design, Resilience and Rehabilitation of Structures-CoRASS 2019, Coimbra, Portugal, 16-18 October 2019.

34. Della Torre, S. Conservazione programmata: I risvolti economici di un cambio di paradigma. Il Cap. Cult. Stud. Value Cult. Herit. 2010, 1, 47-55. [CrossRef]

35. Ferretti, V.; Bottero, M.; Mondini, G. Decision making and cultural heritage: An application of the Multi-Attribute Value Theory for the reuse of historical buildings. J. Cult. Herit. 2014, 15, 644-655. [CrossRef]

36. Oppio, A.; Bottero, M.; Ferretti, V.; Fratesi, U.; Ponzini, D.; Pracchi, V. Giving space to multicriteria analysis for complex cultural heritage systems: The case of the castles in Valle D'Aosta Region, Italy. J. Cult. Herit. 2015, 16, 779-789. [CrossRef]

37. Wang, H.; Zeng, Z. A multi-objective decision-making process for reuse selection of historic buildings. Expert Syst. Appl. 2010, 37, 1241-1249. [CrossRef] 
38. Pinto, M.R.; De Medici, S.; Senia, C.; Fabbricatti, K.; De Toro, P. Building reuse: Multi-criteria assessment for compatible design. Int. J. Des. Sci. Technol. 2017, 22, 165-193.

39. Fusco Girard, L.; De Toro, P. Integrated spatial assessment: A multicriteria approach to sustainable development of cultural and environmental heritage in San Marco dei Cavoti, Italy. Cen. Europ. J. Oper. Res. 2007, 15, 281-299. [CrossRef]

40. Della Spina, L. Adaptive Sustainable Reuse for Cultural Heritage: A Multiple Criteria Decision Aiding Approach Supporting Urban Development Processes. Sustainability 2020, 12, 1363. [CrossRef]

41. Trovato, M.R.; Nocera, F.; Giuffrida, S. Life-cycle assessment and monetary measurements for the carbon footprint reduction of public buildings. Sustainability 2020, 12, 3460. [CrossRef]

42. Fernandez-Antolin, M.; Del Río, J.M.; Costanzo, V.; Nocera, F.; Gonzalez-Lezcano, R. Passive design strategies for residential buildings in different Spanish climate zones. Sustainability 2019, 11, 4816. [CrossRef]

43. Giuffrida, S.; Gagliano, F.; Nocera, F.; Trovato, M.R. Landscape assessment and economic accounting in wind farm programming: Two cases in Sicily. Land 2018, 7. [CrossRef]

44. Fiore, P.; Sicignano, E.; Donnarumma, G. An AHP-Based Methodology for the Evaluation and Choice of Integrated Interventions on Historic Buildings. Sustainability 2020, 12, 5795. [CrossRef]

45. Della Spina, L. Evaluation Decision Support Models: Highest and Best Use choice. Procedia-Soc. Behav. Sci. 2016, 223, 936-943. [CrossRef]

46. Lo Faro, A.; Mondello, A.; Salemi, A. Compatible Reuse of the Single Hall Churches in Catania (IT): Thinking and Proposals. Vitr. Int. J. Archit. Technol. Sustain. 2018, 3, 37-53. [CrossRef]

47. UNI 11182:2006. Cultural Heritage. Natural and Artificial Stone. Description of the Alteration. Terminology and Definition. Ente Italiano di Normazione. 2006. Available online: https:/ /infostore.saiglobal.com/en-au/Standards/UNI-11182-2006-1071699 _SAIG_UNI_UNI_2497752/ (accessed on 25 October 2020).

48. Vergès-Belmin, V. Illustrated Glossary on Stone Deterioration Patterns; ICOMOS: Paris, France, 2008.

49. Lo Faro, A.; Miceli, A. Sustainable Strategies for the Adaptive Reuse of Religious Heritage: A Social Opportunity. Buildings 2019, 9, 211. [CrossRef]

50. Forster, A. Building conservation philosophy for masonry repair: Part 2-“Principles". Struct. Surv. 2010, 28, 3. [CrossRef]

51. Saija, L.; Pappalardo, G. An argument for action research-inspired participatory mapping. J. Plan. Educ. Res. 2018. [CrossRef]

52. Pappalardo, G. Community-Based Processes for Revitalizing Heritage: Questioning Justice in the Experimental Practice of Ecomuseums. Sustainability 2020, 12, 9270. [CrossRef]

53. Schauwecker, T.; Pappalardo, G.; Gravagno, F. Collaborative design-build as a strategy for community involvement: The experience of Contrada Nicolò along the Simeto River, Sicily, Italy. Landsc. Res. Rec. 2018, 7, 173-188.

54. Plevoets, B.; Sowińska-Heim, J. Community initiatives as a catalyst for regeneration of heritage sites: Vernacular transformation and its influence on the formal adaptive reuse practice. Cities 2018, 78, 128-139. [CrossRef]

55. Rey-Pérez, J.; Domínguez-Ruiz, V. Multidisciplinarity, Citizen Participation and Geographic Information System, Cross-Cutting Strategies for Sustainable Development in Rural Heritage. The Case Study of Valverde de Burguillos (Spain). Sustainability 2020 12, 9628. [CrossRef]

56. Lo Faro, A.; Miceli, A. Riuso ed accoglienza: Una proposta per villagonia (ME). In Proceedings of the IV International Conference ReUSO, Messina, Italy, 11-13 October 2018.

57. Cornudella, J. Por una Arquitectura más Empática. Humanizando los Entornos Sanitarios. Available online: http:/ /hospitecnia. com/arquitectura/arquitectura-empatica-humanizando-entornos-sanitarios/ (accessed on 25 October 2020).

58. Cunsolo, R.; San Vincenzo Hospital, Taormina, Italy. Information and Statistical Data about the Divisions of Medical Oncology and Pediatric Heart Surgery. Personal communication, 2017.

59. Guccione, A. Costruire nel Costruito: Un'ipotesi di Riuso per l'ex Convento dei Minori Osservanti Sito in Grammichele (CT). Master's Thesis, University of Catania, Catania, Italy, 2016.

60. Todres, L.; Galvin, K.T.; Holloway, I.M. The Humanization of Healthcare: A Value Framework for Qualitative Research. Int. J. Qual. Stud. Health Well-Being 2009, 4, 68-77. [CrossRef]

61. Timpanaro, R. Un'oasi per l'oasi. Proposta di Riqualificazione Dell'ex Convento di S. Francesco e Dell'immacolata a Troina (EN). Master's Thesis, University of Catania, Catania, Italy, 2019.

62. Chierchi, P.F. Adaptive Reuse of Abandoned Monumental Building as a Strategy for Urban Liveability. Athens J. Archit. 2015, 1, 253-270. [CrossRef]

63. Carbonara, G. Presentazione degli atti del convegno internazionale Dio non abita più qui? Dismissione dei luoghi di culto e gestione integrata dei beni culturali ecclesiastici. In Proceedings of the La Valorizzazione del Patrimonio Ecclesiastico, Online event, Koinè: XIX International Exibition of Sacred Art, Vicenza, Italy, 26-27 October 2020.

64. Radice, F. AURA. Un Metodo Analitico a Scala Urbana per valutare la Trasformabilità delle Chiese Sottoutilizzate. In Proceedings of the La Valorizzazione del Patrimonio Ecclesiastico, Online Event, Koinè: XIX International Exibition of Sacred Art, Vicenza, Italy, 26-27 October 2020.

65. Longhi, A. Tecniche di Analisi Multicriteria a Scala Territoriale per l'Utilizzo e la Valorizzazione del Patrimonio Architettonico Religioso. In Proceedings of the La Valorizzazione del Patrimonio Ecclesiastico, Online Event, Koinè: XIX International Exibition of Sacred Art, Vicenza, Italy, 26-27 October 2020. 